\title{
Addiction or Disorder? Using the BIAS Map Model to Explain the Stigmatizing Effects of News Media Labels for Opioid Use Disorder
}

Kylie J. Wilson

West Virginia University, kw0059@mix.wvu.edu

Follow this and additional works at: https://researchrepository.wvu.edu/etd

Part of the Health Communication Commons, and the Mass Communication Commons

\author{
Recommended Citation \\ Wilson, Kylie J., "Addiction or Disorder? Using the BIAS Map Model to Explain the Stigmatizing Effects of \\ News Media Labels for Opioid Use Disorder" (2020). Graduate Theses, Dissertations, and Problem \\ Reports. 7554. \\ https://researchrepository.wvu.edu/etd/7554
}

This Dissertation is protected by copyright and/or related rights. It has been brought to you by the The Research Repository @ WVU with permission from the rights-holder(s). You are free to use this Dissertation in any way that is permitted by the copyright and related rights legislation that applies to your use. For other uses you must obtain permission from the rights-holder(s) directly, unless additional rights are indicated by a Creative Commons license in the record and/ or on the work itself. This Dissertation has been accepted for inclusion in WVU Graduate Theses, Dissertations, and Problem Reports collection by an authorized administrator of The Research Repository @ WVU.

For more information, please contact researchrepository@mail.wvu.edu. 
Addiction or Disorder? Using the BIAS Map Model to Explain the Stigmatizing Effects of News Media Labels for Opioid Use Disorder

\author{
Kylie J. Wilson
}

Dissertation to be submitted

to the Eberly College of Arts and Sciences

at West Virginia University

in partial fulfillment of the requirements for the degree of

Doctor of Philosophy in Communication Studies

\author{
Elizabeth L. Cohen, Ph.D., Chair \\ Matthew M. Martin, Ph.D. \\ Christine E. Rittenour, Ph.D. \\ Danielle M. Davidov, Ph.D. \\ Department of Communication Studies
}

\author{
Morgantown, West Virginia \\ 2020
}

Keywords: stigma, BIAS Map, labeling, opioid use disorder, addiction

Copyright 2020 Kylie J. Wilson 


\begin{abstract}
Addiction or Disorder? Using the BIAS Map Model to Explain the Stigmatizing Effects of News Media Labels for Opioid Use disorder
\end{abstract}

\title{
Kylie J. Wilson
}

The stigma surrounding opioid use disorder is often reinforced by the language that the general public and institutions use to talk about people with the disorder. This is consistent with labeling theory, which contends that labels are vehicles for social categorization and stereotypes (e.g., Link \& Phelan, 1999). Studies have found that labels such as "addict" trigger a negative implicit bias, compared to labels such as "opioid use disorder" (e.g., Ashford, Brown, Ashford, \& Curtis, 2019; Corrigan, Kuwabara, \& O'Shaughnessy, 2009; Goodyear, Haass-Koffler, \& Chavanne, 2018) but the ingroup based cognitive and emotional process through which these affect public stigma has not been explored in detail. This dissertation employs the Stereotype Content Model (SCM) and the Behaviors from Intergroup Affect Stereotypes (BIAS) Map to explain how two different labels for opioid use disorder used in a news article can differentially impact people's stereotypes (warmth and competence), emotions, and behavioral tendencies toward people with opioid use disorder. For this study, an online experiment was used to compare MTurk users' $(N=348)$ perceptions of opioid users, after reading either a news article about a proposed community treatment center for "people who are addicted to opioids" or "people with opioid use disorder." Contrary to predictions, the label "addict" elicited slightly less contempt compared to "disorder." This was the only difference between the two experimental conditions. Notably, however, compared to a comparison condition, the "addict" label also increased perceptions of competence, decreased feelings of contempt, and increased a desire to engage in passive facilitation. These results may be attributable to the use of person-first language (PFL) in the experimental articles. When using PFL, the focus is shifted from the disorder or diagnosis, and brings attention back to the person instead (Collier, 2012; CSAT, 2004). Describing "addicts" as people with addictions may have emphasized their individuality. This underscores the need for journalists to use PFL when reporting on the opioid crisis. However, notably, the same positive effects of PFL did not occur when PFL was paired with the label "disorder," suggesting that the public may have a more difficult time distancing themselves from the negative associations they have with "disorders." Although the labels in this study did not have the predicted effects, many of the variable relationships in this research are consistent with predictions of the BIAS Map (Cuddy, et al., 2007). For example, warmth was negatively correlated with contempt and positively correlated with pity, and pity was correlated with active facilitation. A notable deviation was that felt warmth for people with OUD was also associated with greater support for policies that could help and harm them. This suggests that respondents probably regarded the penalization policies as a "tough love" strategy, possibly reflecting a misguided desire to help people with OUD. 


\section{DEDICATION}

I would like to dedicate this dissertation to my mom, Lorrie Gibbons. My mom was diagnosed with lung cancer right before I defended my dissertation prospectus, and even through her diagnosis, she continues to make me a priority. She has always encouraged me to do the best I can, and that has not changed. My mom has always been my biggest cheerleader in everything I

have done. She is not just my mom, but also my best friend, and my favorite person. It has been a struggle to be in WV (630 miles from IL) while she goes through scans, testing, and treatment, but I know she wants me to be here to finish this dissertation up and graduate. This is what has pushed me to get through my dissertation and doctoral program. This is for you, mom. I love you more than there are stars in the sky and fish in the sea. Look, mom... your little moon did it. 


\section{ACKNOWLEDGEMENTS}

First and foremost, I would like to express my utmost gratitude to every person in this department for not only taking a chance on me as a student, but also putting up with me for three years. There are so many wonderful individuals that I need to thank for getting me to where I am today.

To begin with, I would like to thank my amazing advi-saur, Elizabeth Cohen. You are dino-mite! I would not have made it throughout the program without your guidance and support, not only in classes and for my dissertation, but in life in general. When everything seemed to crumble underneath me at the start of my third year, you were there and looked after me like my mom would. From blood clots, to a broken foot, to being scared for my mom, you have been there for me through it all. This has been one of the most challenging, yet rewarding times of my life, and I would not be at the finish line without you. We made it through all the boulders this year and came out on the other side. Thank you for being you and looking after me. Thank you for working with me and pushing through my detailed tribute to my wrongness, because that is science. You are a badass motherclucker, and I am forever thankful to have had you advise me through all this.

To my dissertation committee, Matt Martin, Christy Rittenour, and Danielle Davidov, thank you for putting in as much effort and time into my work to make my dissertation research and manuscript the absolute best it could be. Dr. Martin, thank you for always having kind words to share, and a great story to go along with it. You were extremely patient with me and my "Kylie-isms" in my writing, and I cannot thank you enough for that. I appreciate all your help and support, not only as a committee member, but as a student as well. My first class at WVU (Communication Theory) was with you, and I feel like I got so much out of that class that I still 
use in my everyday life. Also, thank you for making it official in Baltimore and telling everyone that I was your favorite current doctoral student... it's on my CV because that is the highlight of my career. Dr. Rittenour, you have been such a guiding and positive light in my life throughout this program and dissertation process. I couldn't have asked for anyone better to be on my committee, you truly made me feel like I was a big shot scholar like y'all. I am forever thankful that you took the time to help on my committee because you made me think about my topic in different perspectives than originally planned, making my dissertation the best it could be, but also making me think about things in the real world differently. Graduating is a humbling, and exciting experience, but I will miss the sing-a-long CD from you and your kiddos each Christmas. I appreciate all you have done for me. Last, but certainly not least, Dr. Davidov, thank you for not only agreeing to be on my committee, but for also providing me with knowledge from a new field. I loved your prevention and intervention course and was very excited to be able to tie that into my dissertation topic. Your class taught me invaluable knowledge and skills that I will carry with me throughout my career. Thank you for putting so much energy into this process for me, I am truly thankful for you.

I would also like to give a few special shout outs within the department: Dr. Goodboy, Joy, and Terri. Y'all have made such an impact on my life and education, and I am so appreciative for you all. First off, Dr. Goodboy, you took a chance on me. Even when I didn't believe I should be here, you believed in me. You were the first person to believe that I should be in the Ph.D. program at WVU. I am forever grateful that I was able to meet with you and Dana in Philly. You both made me feel like WVU was the right place for me, and three years later, I can say without a doubt that you were right. Dr. Goodboy, thank you for all of your support through all my ailments, injuries, and periods of uncertainty throughout this last year as well. Having 
your support made me feel more comfortable making some of the tougher decisions I had to make this year. Joy and Terri, thank you for being the wonderful, strong, patient women that you are. Not only did you deal with the problems in the department flawlessly, you put up with me for three years. You can ask Rich, that is not an easy task. I appreciate all of your help setting up travel, paperwork, and room scheduling. For all the work you have done for myself and the rest of the faculty and staff, you both deserve a Ph.D. We could not function without you, and I absolutely could not have made it through this program without you both.

To my cohort members, Stephen and Mckay, I could not do it without you. You both kept me sane, watched my back, helped cover classes, and make it through comps, defenses, and now dissertations. I am so grateful that I was in a cohort with both of you and thankful to have a lifelong friendship. I hope you both know that even though Stephen will be in Florida and Mckay will be in Wyoming (I still don't know where I'll be...), you both have a friend whenever you need me. I am so very glad that you both have an exciting path to continue on and will be around to visit you soon! Thank you for checking in on me, cheering me up, putting up with my obnoxiousness, and Monday Night Wings. Y'all are the best, and I couldn't have done this without you. Thank you for being you, please never change.

To the pals I met here, the people this program selected for me, you are so important to me and I hope you remain a constant in my life (even after I'm long gone from WVU). Margo and Kaitlyn, you both got me through my first year. From family dinners, wine nights, nail appointments, conference roomies, and carpooling to class, you both are so important to me and will forever hold a special place in my heart. I can't thank you enough for being the genuinely sweet, amazing women you are. You both believed in me when I didn't believe in myself, and that means the world to me. I love you both very much and can't wait for our next girl's night! 
Sara, thank you for being my doc mom. I loved that I had someone here to watch out for me like my mom would, whether that is taking me home from the office or making sure I got home safe after a night out. You are a wonderfully, positive, and guiding force in my life and I am so very thankful to have been in the program with you. I love you! Nora, Michelle, and Erin, y'all are my little baby docs, and I am so very happy I got to overlap a year in this program with you. You three kept my worries low, my smiles big, and my heart happy. Make sure to keep the creepy shrine up for Stephen and I... it will be like we never left. I love you three so much and am forever grateful to have you as my little baby docs - quack quack.

To my wonderful mom, dad, fake dad, brother, niece and King. I owe the world to you all. Never in my wildest dreams did I think that I would be Dr. Kylie J. Wilson, Ph.D., but you all pushed me to be my best, and here we are. It has been incredibly hard for me to be so far away from each of you, but just know that I am working my tail off to get a job closer to y'all. To my mom and fake dad, William, you both have shown me so much love and support throughout my life. I could not have made it this far without you both and I have to be the luckiest lady in the world because I have you to support and love me. I love you both very much! To my late dad, Sean Wilson, you would have been so proud to see your daughter get her Ph.D., even if you would have called me a nerd. To think, you wouldn't let mom spell my name Kyleigh, because in your words, "she's my kid, she'll never learn how to spell that," and now I'm a doctor! I hope that I am making you proud, and hope you know how much I love and miss you. To my brother, Zach and niece, Harper, you are both such weirdos. I would be nothing without you weirdos though. Even being so far away, you both make me feel like I am still right there as a part of the chaos back home. I love when I get calls and hear: "Karl!" "Auuunnnnnttt Kyyyyy" or "Satan," as you so lovingly call me, you two push me to get through this dang 
dissertation and get out. I love you both so much, as Harper says: "be good fam." Kinger Dinger, thank you for being the goodest best boy. I have truly loved having you as a pup, Netflix bingeing, dissertation writing, and snacking with you by my side. Thank you for being such an accommodating pup, and taking to WV like a champ. I love you, Kingsley. To the Ladner family, thank you for treating me as your own and supporting me throughout this entire process. Thank you so much for letting me steal Rich away for three years to move about 10 hours away. You are all such wonderful people, and I am so lucky to have each of you in my life. Thank you for thinking of me as your own, I have definitely thought of you as my own family and not just my boyfriend's family!

Last but certainly not least, Rich, thank you for being the wonderful man that you are. I don't know what I did to deserve such a wonderful person like you, but I am glad that I have you in my life. I am truly the luckiest woman alive. Thank you for pushing me to complete this dissertation, stay on top of coursework and teaching, push through comprehensive exams, and oral defenses. You have made such an impact on my life and believed in me throughout this program. You have made this process better for me, and I feel truly blessed to have someone by my side to lean on when I need to. You have taught me how to be a more patient, caring, and loving person, and I am forever indebted to you. In all honesty, you deserve this Ph.D. just as much as I do for all you have had to put up with (i.e., Kylie crying on the living room floor, irritated Kylie being sassy toward you for no reason, stressed Kylie who is just a mess and has no clue what is going on in life). You da real MVP. You have been my support system through all of this, and even been "a part" of this department, and I cannot thank you enough. I have heard several times that people in my department like you better, and I can honestly see why. You have those luscious locks (that Dr. Goodboy loves to smell), a chill personality, and are so caring 
toward other people. Dr. Myers loves when my "husband" (AKA Rich) comes around because he is always down to help a good cause. Thank you for being my support system, love of my life, pushing me to get through this program, ugly cry after "winning" my dissertation and forcing me to watch Game of Thrones. I now know that I am Tyrion Lannister... "That's what I do, I drink and I know things." Rich, you are literally the best, I am so lucky to have you in my life, I love you so much! 
TABLE OF CONTENTS

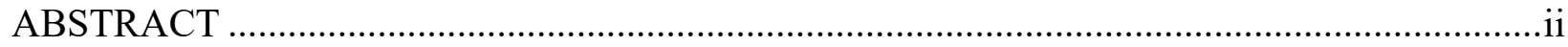

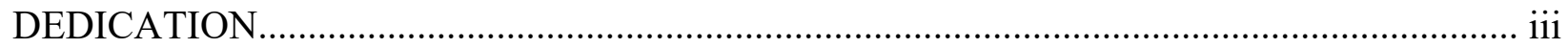

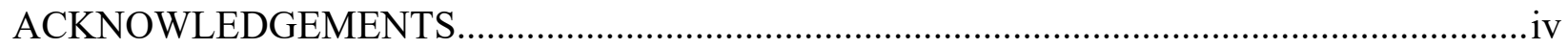

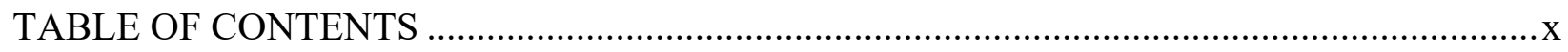

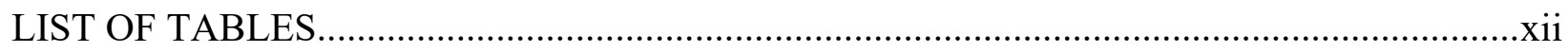

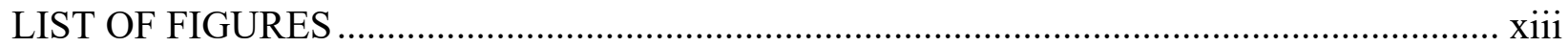

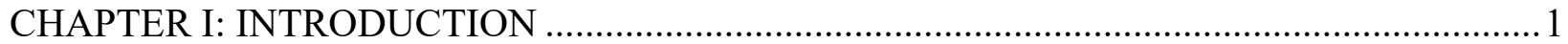

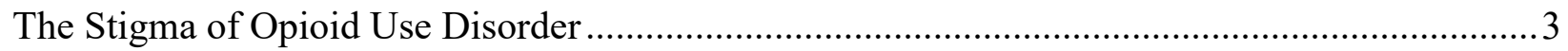

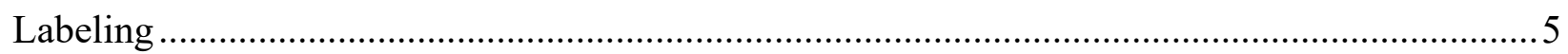

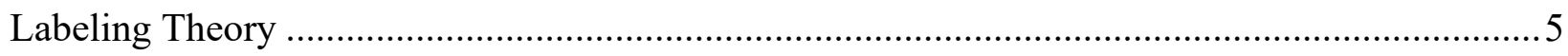

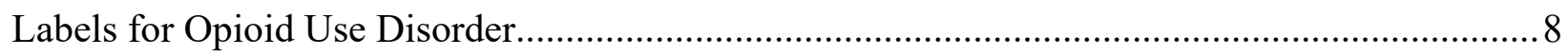

Stereotype Content \& BIAS Map Models .............................................................................

Stereotype Content, Emotions, and Behavior Toward People with Opioid Use Disorder ............. 14

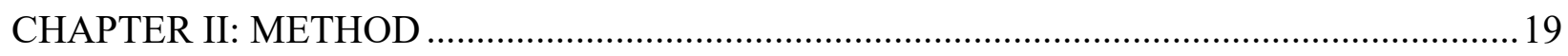

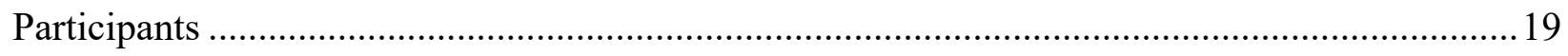

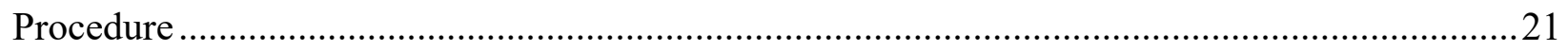

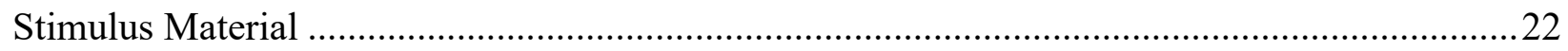

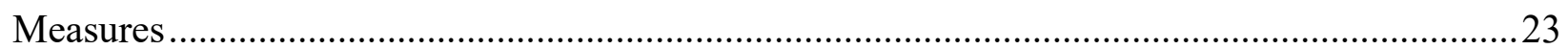

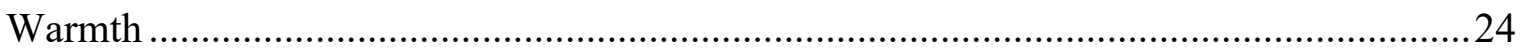

Competence

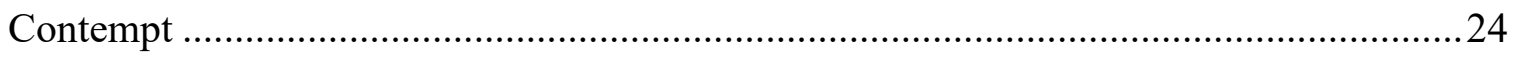

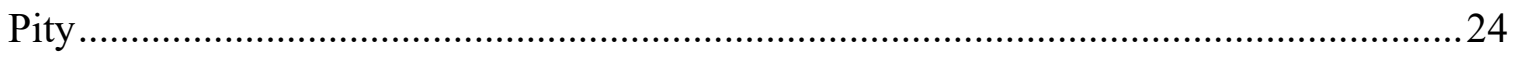

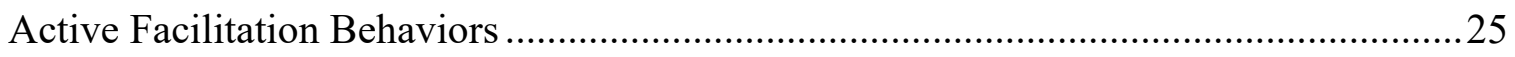

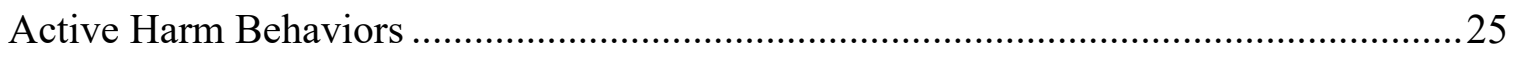

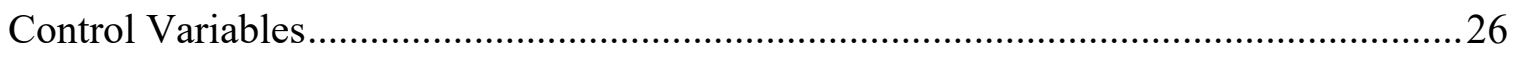

Personal Experience with Substance Use Disorder .............................................26

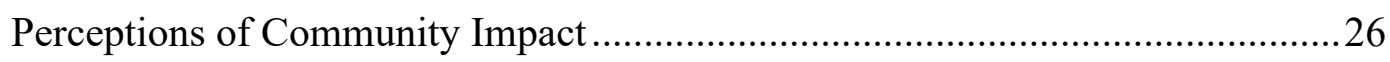

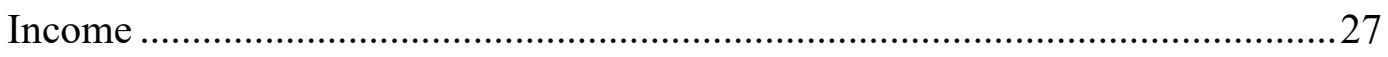

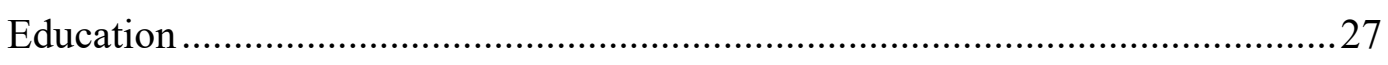

Age

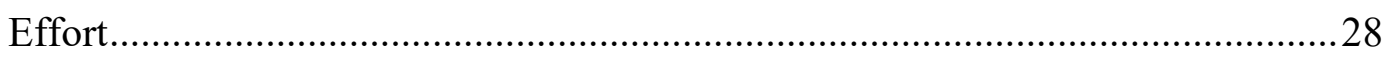

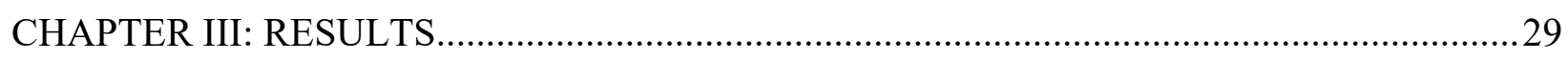

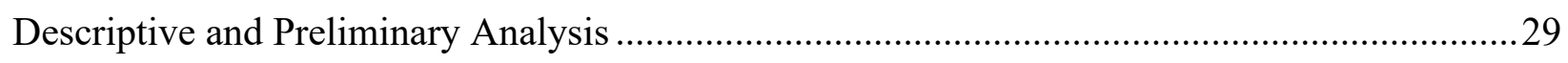

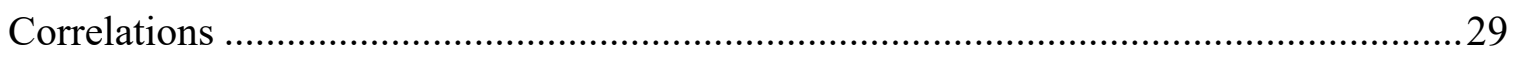


Comparison Group Analysis ...............................................................................

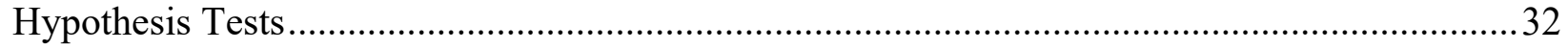

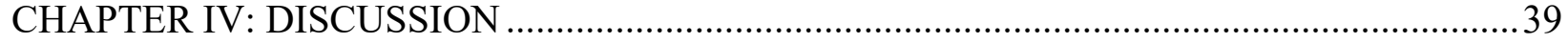

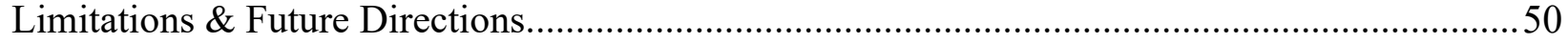

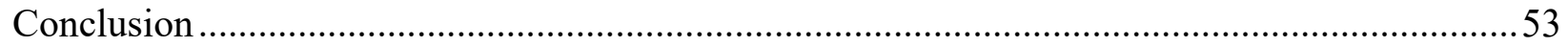

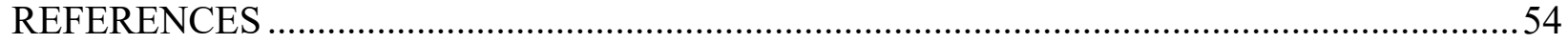

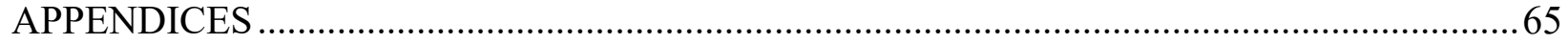

Appendix A: Survey Advertisement...................................................................65

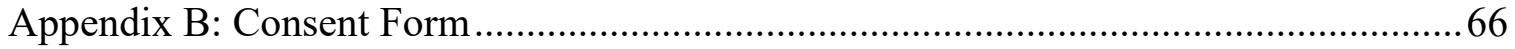

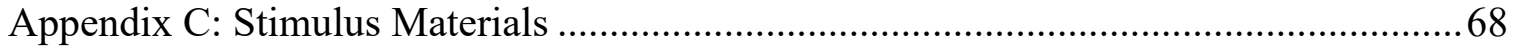

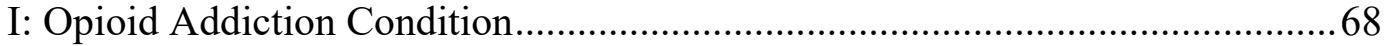

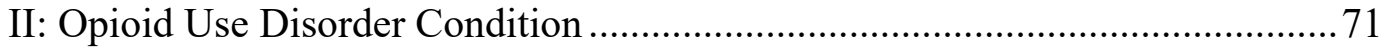

III: Banning Pit Bulls - Comparison Condition...................................................... 74

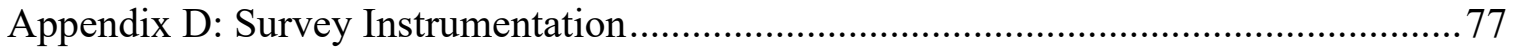


LIST OF TABLES

TABLE 1. Mean Comparisons Across Experimental Conditions ...............................................32

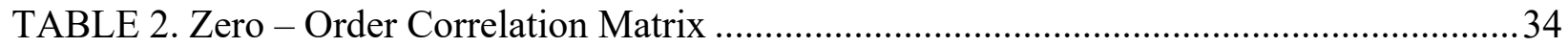

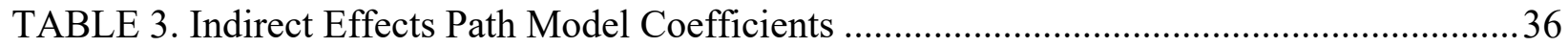

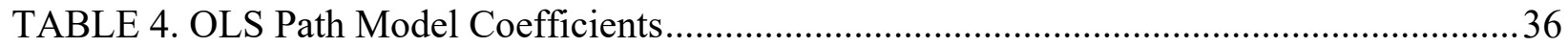

TABLE 5. Indirect Effects Path Model Coefficients .................................................................... 38

TABLE 6. OLS Path Model Coefficients........................................................................................... 38 


\section{LIST OF FIGURES}

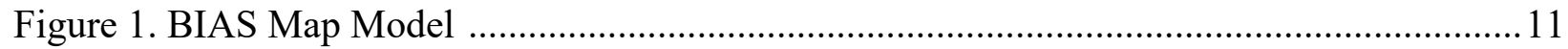

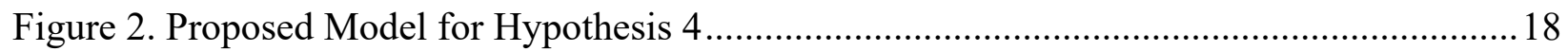

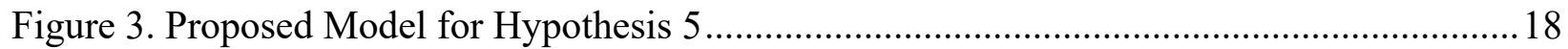

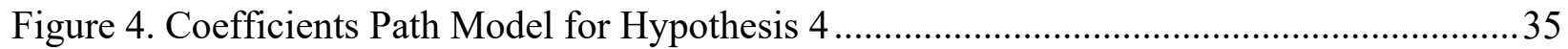

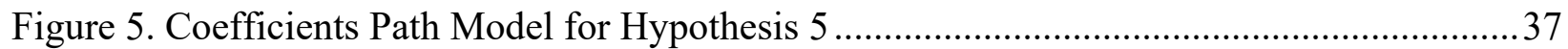




\section{CHAPTER I}

\section{Introduction}

The stigma attached to people who have an opioid use disorder (OUD), a disease characterized by a person's inability to control their use of opioids, is devastating because it leads to discriminatory behaviors, such as lack of employment opportunities, abuse, or imprisonment toward these individuals (Corrigan \& Watson, 2002). The reasons that conditions like addiction are stigmatized are varied and complex, but labeling theory argues that the terms people use to describe stigmatized conditions perpetuates the stereotypes, prejudice and discrimination associated with them (e.g., Link, 1987). Research indicates, for instance, that labels such as opioid "abuser" or opioid "addict" can prime negative responses toward people to whom these labels are attached (Ashford et al., 2018; Corrigan, Kuwabara, \& O’Shaughnessy, 2009; Goodyear, Haass-Koffler, \& Chavanne, 2018; Kelly, Dow, \& Westerhoff, 2010; Kelly \& Westerhoff, 2010). There is, however, evidence that "opioid use disorder" may be a less stigmatizing label (Kelly, 2017; Kelly, et al., 2010; Kelly \& Westerhoff, 2010). Nonetheless, prominent treatment programs such as Alcoholics Anonymous and Narcotics Anonymous continue to use terms such as "addict" and "abuser" because individuals using these treatment programs self-categorize as "addicts" or "abusers." Stellin (2018) argues that this is because the mental health and medical diagnosis aspect of opioid use disorder is unclear to the average person, but the general public is familiar with terms like "opioid addict."

Similarly, although research on how the media refers to people with OUD is sparse, there is reason to suspect that journalists may also rely on stigmatizing terminology in the interest of making a potentially complex condition seem simpler to the public. As one health journalist stated in an interview about their reporting practices, "we have to serve our readers first and we 
can't use terms that don't have meaning for them or aren't clear" (Stellin, 2018, p. 40). Because journalists' duty is to provide information to consumers in a simple manner that is easily understood, they may excuse their use of the term "addict" in the interest of using labels that they believe are more familiar to the public. But the very reason that the label "addict" may be easier for the public to digest is exactly why it can be so stigmatizing. From a social identity perspective (Tajfel \& Turner, 1986), labels like "addict" make it easier for people to lump people with OUD into a single, unsavory social category. By using the term "addict," journalists are encouraging the public to use this group categorization, thereby inadvertently perpetuating the stigma attached to the group.

Ultimately, however, the implications of journalists' label choices on public perceptions of people with OUD and public willingness to help (or harm) people with OUD are not well understood. The current study is aimed at investigating the influence of news labels for people with OUD on public perceptions of, and behavioral intentions toward people with OUD. In an online experiment, participants will be asked to read a short news article about either "opioid addicts" or people with "opioid use disorder." This study will use the behaviors from intergroup stereotypes and affect map (BIAS Map; Cuddy, Fiske, \& Glick, 2007) as a theoretical framework for understanding how these different labels can influence people's behavior towards this group. Specifically, this research will examine stereotypes and emotions toward people labeled as having an "opioid addiction" or an "opioid use disorder" as mediators of the effect of these labels on behavior. The use of opioid addiction and opioid use disorder does not make these terms unparalleled but can show which term the media uses can lead to more problematic effects for the categorized group. The findings of this research will extend existing research on the effects 
of labels for OUD by explaining some of the mechanisms behind why some labels are more or less stigmatizing.

\section{The Stigma of Opioid use disorder}

In his seminal work on the subject, Goffman (1963) defined stigma as some "attribute that is deeply discrediting," a characteristic that reduces the stigmatized individual "from a whole and usual person to a tainted, discounted one" (p. 3). Public or social stigma occurs when the population stigmatizes a social group of people, preventing them from obtaining full social acceptance. But individuals can also self-stigmatize when they believe and internalize the negative attitudes that others hold about their group (Corrigan \& Watson, 2002). The stigmatization process typically involves applying stereotypes to a group, feeling prejudice toward them, and discriminating against them (Corrigan \& Watson, 2002). Stigma defines attitudes toward outgroup members through stereotypes, prejudice, and discrimination. Stereotypes are social beliefs (typically negative) that people hold about particular groups. Prejudice is the cognitive emotional reactions that people have in response to the group, often linked to the stereotype. Finally, discrimination is a negative behavioral response, usually in the form of avoidance or harmful treatment of members of the stigmatized group (Corrigan \& Watson, 2002). Feldman and Crandall (2007) state that the more the public believes the stereotype about the stigmatized group (e.g., people with addiction are criminals), the more prevalent their prejudice and discrimination against that group.

A number of studies have investigated the specific stereotypes surrounding OUD. For instance, research has shown that individuals with a OUD tend to be perceived as dangerous, criminal, erratic and unpredictable (Corrigan, Green, Lundin, Kubiak, \& Penn, 2001; Crandall \& Reser, 2005; Mushtaq, Mendes, Nikalaou, \& Luty, 2015; Yang, Wong, Grivel, \& Hasin, 2017). 
Because substance use is perceived to be within the control of the user, people with OUD are also often stereotyped as poor decision makers (Pescosolido, Monahan, Link, Stueve, \& Kikuzawa, 1999; Yang et al., 2017). The substance that tends to be the most negatively perceived is heroin, stemming from the stereotype that injection drug users are dangerous (Mushtaq, et al., 2015; Yang, et al., 2017).

In a systematic exploration of the stereotypes, prejudices, and discrimination associated specifically with drug use, Nieweglowski et al. (2017) conducted community-based participatory research with a focus group consisting current and former drug users, family members, and members of the medical community. Consistent with other research on OUD they found that much like other mental illnesses (e.g., schizophrenia, personality disorders, bipolar disorder), people tended to characterize people with OUD as being dangerous, weak, rash, uneducated, selfish, promiscuous, sneaky, blame-worthy, and self-destructive (du Pre, 2014; Harvard Health, 2011; Volavka, 2013). In terms of prejudice, participants expressed feelings of fear, anger, and disgust toward people with OUD, as well as more subtle feelings of indifference, sadness, and pity. Dehumanization, social rejection and avoidance, denial of life opportunities and support, and acts of suspicion emerged as forms of discrimination against people with OUD. Following up on this study, Nieweglowski et al. (2019) conducted exploratory factor analyses on items designed to operationalized stereotypes, prejudice and discrimination toward OUD. Notably, they asked participants in this study to assess the truth of how much the public stereotypes, prejudices, or discriminates against "people who are addicted to opioids" (i.e., people who abuse opioids rather than "people with opioid use disorder." Their results revealed a four-factor solution for stereotypes of people with OUD. The four themes that emerged were the stereotype of them being reckless, unreliable, inadequate, and threatening. Anger, pity, and dread emerged 
as prejudice factors, and invalidation (e.g., avoidance and suspicion) and restriction (e.g., denying services and dehumanizing) emerged as two factors of discrimination. Additional analyses showed that women were more likely to endorse restrictive forms of discrimination against people with OUD than males.

The stigma associated with OUD is problematic because it can be socially isolating and is non-conductive to recovery. Self-stigmatization can also damage people with OUD psychologically and hurt their chances for recovery (Foster, 2017). As stated by the Department of Health (2009), stigmatization for addiction leads to isolation and avoidance behaviors from other people and activities. When people with OUD internalize the stigma, they may be more hesitant to disclose information about their disorder and seek treatment (Foster, 2017). Additionally, people with OUD who self-stigmatize exhibit decreased levels of self-efficacy and self-esteem which can negatively impact their willingness to solicit help and recover (Kushner \& Sher, 1991; Corrigan \& Watson, 2002; Wright, Gronfein, \& Owens, 2000). According to Matthews, Dwyer, and Snoek (2017), individuals with OUD who self-stigmatize are at an increased risk for of looping, the cyclical process of repeatedly attempting to be sober, followed by relapsing.

\section{Labeling}

Labeling Theory. The stigma surrounding OUD is often reinforced by the language that the public and institutions use to talk about OUD. Olsen and Sharfstein (2014) point out that recovering patients are often labeled "clean," which implies that they were somehow dirty before. These scholars also note that while the label "junkie" is often used to describe people with SUD, there are usually no such derogatory terms to describe other types of medical conditions like suffering from thrombosis. Furthermore, as Tempalski, Friedman, Keem, Cooper, 
and Friedman (2007) contend, political efforts to frame drug crises as a "war on drugs," and law enforcement efforts that equate people with OUD and criminals has contributed to the broad socio-cultural stigmatization of people with OUD. Even the "Just Say No" slogan popularized by Nancy Reagan's campaign against drug use in the 1980's affirms the stereotype that people with OUD are personally to blame for their condition (e.g., they cannot say "no").

For over half a century, scholars have recognized that the terms people use to label social groups has a direct impact on how the groups are stigmatized. Theories and perspectives on how the labels, or terms used to describe different groups can influence stigma is collectively referred to as labeling theory (Link, 1987; Link, Cullen, Struening, Shrout, \& Dohrenwent, 1989; Link \& Phelan, 2001; Scheff, 1966). Generally speaking, labeling theory concerns itself with how labels act as a glue that connects a group of people to negative stereotypes, prejudice, and discrimination. According to labeling theory, labels fundamentally reduce the essence of a who a person is by emphasizing just a few characteristics or traits rather than information about a whole person (Scheff, 1966). The reason that labels function this way is because they capitalize on people's tendencies to categorize themselves and others. Categorization is "the process of understanding what some thing is by knowing what other things it is equivalent to and what other things it is different from" (McGarty, 1999, p. 1). Tajfel and Turner (1986) examined how categorization is used to understand people, social constructs, and how groups fit within the social environment. They explain that awareness of categorizations different than ones' own categorizations (e.g., in-group versus out-group) is enough to engage in discriminatory processes. In an randomized experiment, participants were anonymous, except for their group membership (e.g., Group X or Group Y) and membership number (e.g., X 31). Participants were asked to anonymously and individually award money to other participants in both groups. There 
was not an instance of social interaction between members of either group. However, because participants knew their group membership, the categorization lead to in-group favoritism and discrimination toward the out-group (Tafjel \& Turner, 1986). According to Tafjel and Turner (1986), it does not matter if people see themselves as similar or different from others, but that social categorization and labelling packages individuals into groups that are discrete (e.g., group member or not) and acting discriminatory toward stereotyped groups seems "appropriate" based on social structures. Oakes (2003) argues that labels are an important facilitator of the categorization process. These labels not only lead to self-identification with the label, but also perceptions from the public of identification with the label. The public can be lead to perceptions that do not match actuality, rather an inaccurate interpretation of social groups and the social environment. However, some perceptions do reflect pieces of reality and identities, most labels categorize people based on stereotypes that are not entirely true. This is problematic because it leads to stigmatization of self-categorization (Tajfel, 1978), leading people within the categorized group to align with the inaccurate social environment. Labels are often attached to all social groups, not just social groups who are considered socially deviant in some way and emphasize at least one characteristic of the social group (Jones, Farina, Hastorf, Markus, Miller, \& Scott, 1984; Link \& Phelan, 1999).

Labeling theory has often been applied to understand how labels affect the stigma of mental illness. For instance, Scheff's labeling model $(1966,1984)$, argued that because people are socialized to adopt societally proscribed attitudes towards "the other" such as people with mental illness, labeling someone as a "mentally ill person," constrains people's behaviors toward the person, cueing everyone to treat the person the same. Scheff argued that this uniform treatment from society causes the stigmatized individual to think of this label as part of their 
identity and therefore continue to be mentally ill as a consequence. Link and Phalen (1989) later proposed the modified labeling approach, which did not carryover Scheff's contention that labels have the power to determine whether someone is mentally ill. Instead, the modified labeling approach views labeling as a factor that put peoples at risk for the continuation or recurrence of undesirable conditions that arose for other reasons. The modified labeling approach also puts greater emphasis on how labeled individuals will believe others will respond to the label. Link and Phalen (2001) underscore that the mere anticipation of negative public response to a label can cause labeled individuals to withdraw from others. In this way, labels can result in negative consequences indirectly, by discouraging labeled individuals from seeking interactions that they could potentially benefit from, as with many stereotypes.

Labels for Opioid Use Disorder. Research has shown that different labels for people who engage in what could be considered illicit use of substances can also differentially impact the stigma surrounding these groups. For example, labels such as "substance abuser" and "opioid addict" have been shown to elicit a negative explicit bias, or a conscious, cognitive bias among both the general public and medical professionals alike (Ashford et al., 2018; Corrigan, et al., 2009; Goodyear, et al., 2018; Kelly \& Westerhoff, 2010; Kelly, et al., 2010). In the same vein, Corrigan et al., (2009) found that when "addict" was used as a label, public willingness to help (e.g., inclusion of programs in their neighborhood, halfway houses, clean needle exchange) the individual who uses decreased because the person was perceived as being more blameworthy. Also, the researchers found people preferred greater social distance from a person labeled an "addict," meaning people preferred not to associate with people called addicts, dehumanizing the group members. In another study, Kelly, Dow, and Westerhoff (2010) recruited participants from a hospital and surveyed them about their impressions of an individual with a "opioid use 
disorder" or a "substance abuser." The substance abuser was rated as being more deserving of punishment (e.g., jail or fines), and more blameworthy and in control of their actions, while the individual with the OUD was judged as being more in need of treatment, less responsible for their problems and more deserving of sympathy. In another study, Kelly and Westerhoff (2010) randomly assigned mental health care providers to either read a vignette that referred to an individual as a "substance abuser" or a vignette that referred to the individual as having a "substance abuse disorder" (e.g., categorized group versus individual). Although there was no difference in terms of how these labels affected the providers' perceptions of the person as a social threat or whether they should be referred for treatment, participants rated the person labeled as a "substance abuser" in a vignette as being more culpable for causing his own problems and more deserving of punitive action. Similarly, Goodyear, et al. (2018) showed that a sample of participants recruited from MTurk rated an individual labeled as an "addict" more negatively and as having higher responsibility than an individual with an "opioid use disorder." More recently, Ashford, Brown, and Curtis (2019) determined that participants could more quickly associate negative terms with "addict" compared to "substance use disorder" during an association task. Collectively, these studies explain that labels differentially impact stigmatization around opioid use disorder. However, the stereotype content model (SCM) and behaviors from intergroup affect stereotypes (BIAS) map model may shed light on why these labels have different effects.

\section{Stereotype Content \& BIAS Map Models}

Nearly two decades ago, Fiske (1998) proposed that all stereotypes of different social groups can be categorized along two dimensions: warmth and competence. In this Stereotype Content Model (SCM), warmth refers to an impression of how likeable, sincere and good an individual is, 
and competence is a judgement of how capable they are. The authors argued that these two dimensions are fundamental to impression formation because people need to assess what others' presumed intentions are (i.e., how warm or good natured they are) and they need to size up the others' ability to pursue these intentions (i.e., how competent and capable they are). The interaction of these two dimensions can be illustrated a $2 \times 2$ (warmth $\times$ competence) matrix, which consists of quadrants that represent four categories of stereotyped social groups (e.g., high warmth-low competence, high warmth-high competence, low warmth- high competence, low warmth-low competence). The SCM explains that these stereotypes correspond with people's assessment of a group's status and how competitive they are. Status refers to the perception of individuals' placement within the social structure. Individuals who are high status, such as wealthy people, educated people, and Asians, are typically stereotyped as being high in competence, but low in warmth. Individuals who are perceived as being high in competence and low in warmth tend to be perceived as more competitive and positioned to take resources away from other groups, such as job resources or status. Some examples of groups perceived as high competence and high warmth are middle class, women, and White people. These groups are perceived as generally likeable and have capabilities that do not pose a threat to other groups. Groups typically perceived to be low competence and low warmth include the poor, welfare recipients, and the homeless. They tend to be categorized as unlikeable and unfit. Finally, groups typically stereotyped as low competence and high warmth include older adults, and the physically and intellectually challenged (Fiske, Cuddy, \& Xu, 2002).

The Behaviors from Intergroup Affect Stereotypes (BIAS) Map (Cuddy et al., 2007) extended the SCM by predicting how different affective prejudices (e.g., pity, jealousy, admiration, and contempt) mediate the relationship between stereotype content (perceived 
warmth and competence) and perceived behavioral tendencies. Figure 1 illustrates this framework.

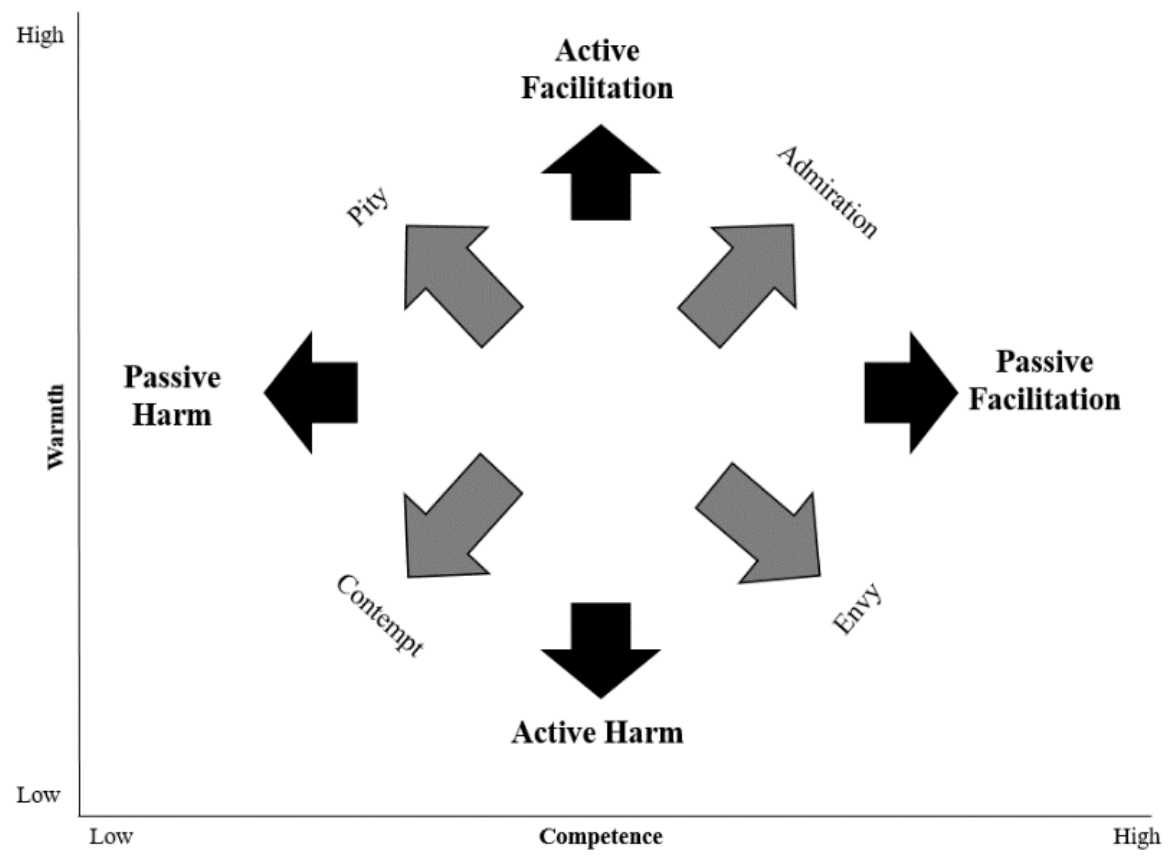

(Cuddy, Fiske, \& Glick, 2007)

\section{Figure 1. BIAS Map}

The BIAS Map classifies behavioral tendencies along two dimensions: a facilitation-harm dimension and an active-passive dimension. The facilitation-harm dimension addresses behavioral intentions toward a social group — how helpful or hindering people are inclined to act toward members of a group. The active-passive dimension categorizes how direct or indirect these behaviors are. Active behaviors involve more effort and are more overt, while passive behaviors involve less effort and are more subtle but still have significant ramifications for group members' well-being. These two dimensions create four categories of behavioral outcomes: active facilitation, active harm, passive facilitation, and passive harm. Active facilitation involves a concerted, prosocial effort to directly assist a person. Examples of active facilitation 
for people with OUD could include engaging in political activism to benefit the group (e.g., signing petitions to bring halfway houses or treatment facilities to one's community to benefit people with OUD), defending a person with OUD from harm, or reducing social distance between oneself and the group by moving in to the same neighborhood as people with OUD without ulterior motives. Active harm behaviors consist of efforts to hurt or hinder the progress of a group. Some examples of active harm toward people with OUD might include engaging in physical violence or harassment of people with OUD or advocating for punitive policy measures, such as extended incarceration sentences. Passive facilitation occurs when individuals perform helping behaviors toward people with OUD indirectly, such as by tolerating their social presence or doing something for a person with OUD in order to get something else. For example, a person might hire a person with an OUD to wash their car, but although this opportunity could be beneficial to the person hired, it would not be motivated by a desire to help (as in the case of active facilitation). Passive harm is when individuals perform hindering or aggressive behaviors toward individuals with OUD indirectly, such as ignoring or neglecting group members, or not supporting policies that could help individuals with OUD (Sadler, et al., 2015). Avoiding making eye contact with a person who has OUD on the street would be an example of passive harm.

According to the BIAS map four emotions mediate the effects of stereotype content (warmth and competence) on behavioral outcomes (active/passive facilitation/harm): contempt, pity, envy, and admiration (Cuddy et al., 2007). Perceptions of high warmth and high competence lead to feelings of admiration. Sadler, et al. (2015) observed that feelings of admiration can be explained by upward social comparison, when people compare themselves to others that they perceive as being better off. These feelings can lead to the behavioral outcomes of active facilitation and passive facilitation. On the other hand, perceptions of low warmth and high 
competence lead to feelings of envy, which leads to active harm and passive facilitation behaviors. The model also predicts that perceptions of low warmth and low competence lead people to feel contempt. Contempt is a feeling related to disgust. Sadler et al., (2015) observed that feelings of contempt can be explained by downward social comparison, where people compare themselves to people who they think are worse off. This emotion leads to active harm and passive harm. Finally, perceptions of low competence along with high warmth leads people to feel pity, due to feelings of kindheartedness and sadness toward the group member (Cuddy, et al., 2007). The model predicts that this emotion should lead to active facilitation and passive facilitation.

Research has confirmed many of the BIAS Map's contentions (Bye \& Herrebroden, 2018; Key, Ceremony, \& Vaughn, 2019; Vaughn, Teeters, Sadler, Cronan, 2017). For example, Bye and Herrebroden (2018) replicated the original BIAS Map study completed by Cuddy, et al. (2007), and found that admiration correlated positively with active and passive facilitation, contempt correlated positively with active and passive harm, pity correlated positively with active facilitation and passive harm, and envy correlated positively with passive facilitation only. Bye and Herrebroden (2018) also showed that the relationship between perceptions of reduced warmth and active harm was mediated by contempt, and the relationship between increased warmth and active facilitation was mediated by pity. Also in support of Cuddy et al. (2007), their results show the relationship between perceptions of competence and passive harm was mediated by contempt.

However, whether people's perceptions of warmth or their perceptions of competence dictate their emotions and behavior appears to depend on which one is more relevant or more salient to them. Becker and Asbrock (2012) explored people's emotional response to ambivalently 
stereotyped groups, or groups that are positively stereotyped in one way (e.g., high warmth) but negatively stereotyped in another (e.g., low competence). The researchers asked participants to read news articles about different ambivalent groups and they manipulated how relevant people's perception of warmth versus competence would be in their judgements by giving people additional details about the groups that would make them seem more or less warm or competent. The results of this study showed that groups who were stereotyped as both low in warmth but high in competence (in this study, "Yuppies,") were treated with active harm when the article emphasized characteristics that made their lack of warmth more relevant than their competence. Specifically, when participants' reading the article had perceptions of warmth that was less than a control group, these perceptions of warmth exerted a greater influence on their behavioral intentions. This effect on was mediated by feelings of contempt. The researchers also found that groups stereotyped as being high warmth and low competence (older adults) were treated with active facilitation, when people's perceptions of their warmth after reading an article about the group exceeded both their perceptions of competence and the perceptions of warmth from a control group. This study demonstrates that the stereotype content that influences peoples' emotions and in turn their behavior is changeable, and that different emotions and behavioral inclinations toward stereotyped groups can be triggered by media messages that emphasize one stereotyped dimension or another.

\section{Stereotype Content, Emotions, and Behavior Toward People With Opioid Use Disorder}

As previously discussed, scholarship on the stigma of opioid use disorder has identified a number of stereotypes, affective prejudices, and behavioral tendencies associated with OUD.

Recall that most recently, Nieweglowski et al. (2019) determined that "addicts" were stereotyped as being reckless, unreliable, inadequate, and threatening. From a stereotype content perspective, 
it seems that addicts would be classified as being relatively low in warmth (evidenced by the belief that they are threatening) and low in competence (evidenced by the belief that they are reckless, unreliable, and inadequate). Therefore, it stands to reason that others will respond to people with OUD with contempt. Along with groups such as welfare recipients, homeless people, and undocumented migrants, "drug addicts" elicit greater contempt and disgust than all other social groups in the U.S. (Fiske, Cuddy, and Glick, 2007). Thus, under normal circumstances, consistent with the BIAS Map (Cuddy, et al., 2007), people should feel contempt for these individuals and seek to actively harm them. This is consistent with Nieweglowski et al.'s (2019) finding that people felt anger towards this group and, consistent with the BIAS Map, they desired forms of restriction (i.e., active harm) against them and they wanted to avoid them (i.e., passive harm).

However, stereotypes of people with OUD may not be fixed. Pity also emerged as a salient emotion felt toward addicts in Nieweglowski et al.'s (2019) study. As previously discussed, pity is typically felt for individuals perceived as being higher in warmth and lower in competence (Cuddy et al., 2007). The varying emotional reactions (both pity and anger) to people with mental health issues or substance use disorders such as OUD, suggests that how people categorize this group in terms of stereotype content could be changeable. In some cases, people with OUD may be perceived as being less cold, at least relatively speaking. Put differently, the stereotype content associated with people with OUD could sometimes be relatively more ambivalent, categorized by low competence, but perhaps higher warmth.

Drawing from labeling theory, it stands to reason that the terms used to describe users could influence how people stereotype people labeled as having a "disorder" or "addiction." As previously discussed, labeling theory explains that labels connect group members to negative 
stereotypes, prejudice, and discrimination. In the context of substance use, it stands to reason that whether a person is labeled as an "opioid addict" or a "person with OUD" could affect what stereotype content is applied to a group (or the degree to which a stereotype is associated with the group). In this particular case, the label may have more impact on perceptions of warmth than competence, as both the labels, "disorder" and "addiction" imply that a person is unwell in some way. But these terms could leave different impressions on people's perceptions of warmth. As with homeless people and welfare recipients, "opioid addicts" may be stereotyped as untrustworthy victims of their own laziness (Fiske et al., 2007). However, people labeled as having "opioid use disorder," may be perceived less coldly if they are perceived to a victim of circumstances outside of their control (Yang, et al., 2017). Put differently, a group with a medical condition may be seen as less blameworthy and warmer in return. By extension, a person with a "opioid use disorder" should also be seen as more sympathetic, eliciting less contempt and greater pity. Accordingly, the following hypotheses were proposed. H1: Compared to the label "opioid addict," the label "opioid use disorder" will elicit perceptions of higher warmth.

H2: Compared to the label "opioid addict," the label "opioid use disorder" will elicit greater feelings of pity.

H3: Compared to the label "opioid addict," the label "opioid use disorder" will elicit less feelings of contempt.

Consistent with the BIAS Map (Cuddy et al., 2007), the differences in stereotype content associated with labels of OUD should lead to different behavioral outcomes, and these effects should be mediated by emotional responses. As predicted, the label "opioid addict" should be associated with relatively lower warmth and greater contempt, and the label "opioid use 
disorder" should be associated with relatively greater warmth and greater pity. The BIAS Map model predicts that both contempt and pity lead to passive harm. For this reason, both labels should be associated with a desire to avoid people with OUD. However, the labels could nonetheless lead to divergent, active behavioral outcomes. Specifically, the label "opioid addict" should lead to a greater desire for active harm, in the form of things such as support for policies that penalize people with opioid use disorder. Consistent with the BIAS Map, this effect should be mediated by reduced warmth and increased contempt. The label "opioid use disorder" should lead to a greater desire for active facilitation in the form of support for policies that would benefit people with OUD. Consistent with the BIAS Map, this effect should be mediated by increased warmth and increased pity. This is predicted in the hypotheses below. The predicted models associated with each hypothesis are illustrated in Figures 1 and 2.

H4: Warmth and contempt will serially mediate the effect of the label "opioid use disorder" on active harm, such that the label will increase perceptions of warmth, which will decrease perceptions of contempt and a desire for active harm.

H5: Warmth and pity will serially mediate the effect of the label "opioid use disorder" on active facilitation, such that the label will increase perceptions of warmth, which will increase perceptions of pity and a desire for active facilitation. 


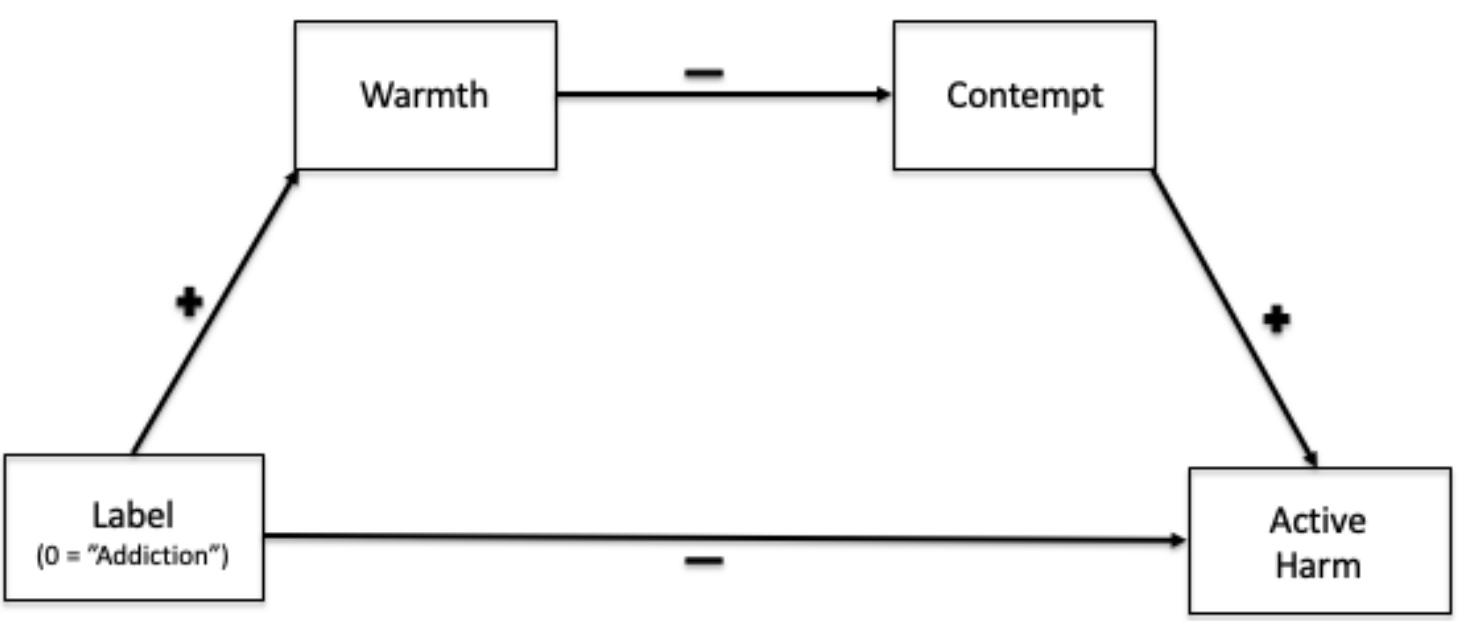

Figure 2. Proposed Model for Hypothesis 4

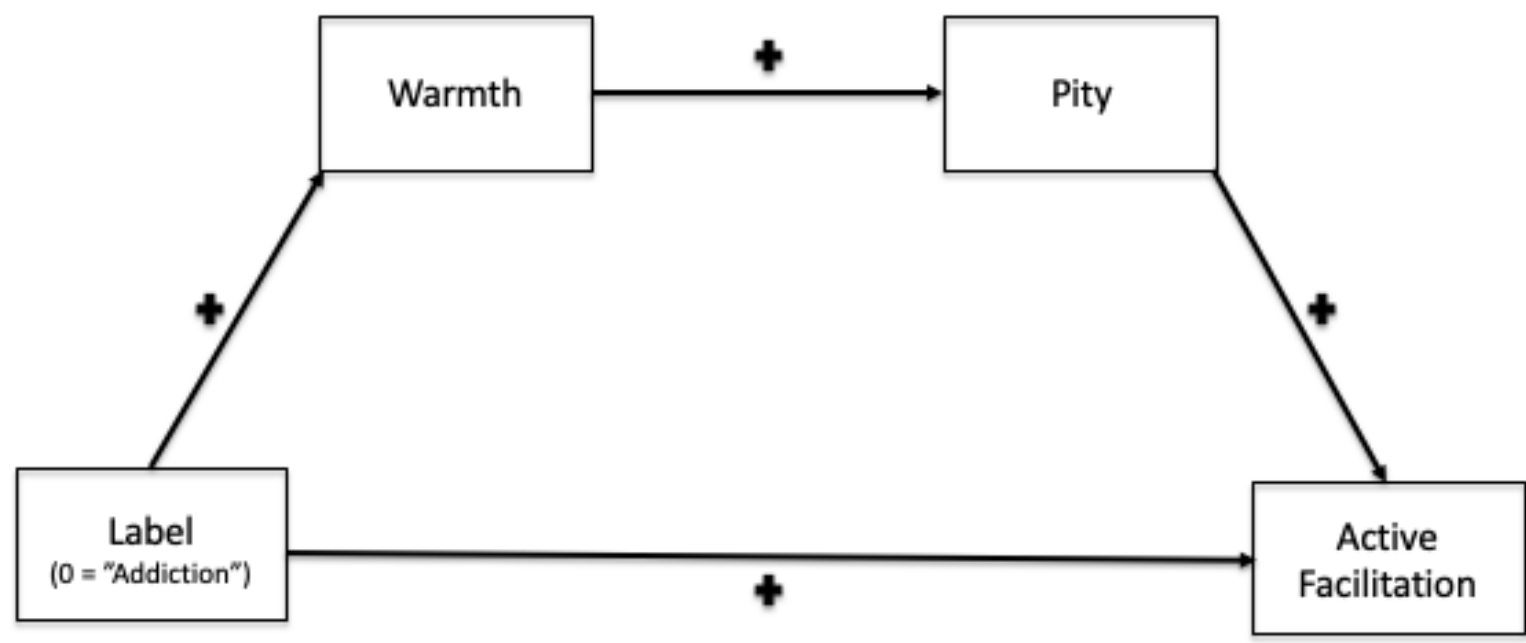

Figure 3. Proposed Model for Hypothesis 5 


\section{CHAPTER II}

\section{Method}

\section{Participants}

Four hundred and five participants were recruited to complete an online experiment using Amazon's Mechanical Turk (MTurk). MTurk is an online crowdsourcing service that permits people to post different tasks that they need to be completed, referred to as human intelligence tasks (HITs). Online surveys are one type of HIT that requestors (e.g., researchers) can create for people to complete. MTurk workers search for tasks they want to complete and accrue money in exchange for completing the HITs (e.g., finishing the posted survey). MTurk workers reside in countries around the world, with most in United States and India (Chandler \& Shapiro, 2016). For this study, limiters were set on MTurk so that only people residing in the United States were eligible to complete the study.

Compared to convenience sampling on college campuses, crowdsourcing sites like MTurk make it easier for researchers to reach larger and more diverse populations (Gosling \& Mason, 2015). Although MTurk samples are diverse, they are not necessarily representative of the general population. According to McDuffie (2019), MTurk workers are typically more educated than the general public. Goodman, Cryder, and Cheema (2013) also argue that they are also typically more likely to be unemployed, and less religious than the general population. McDuffie (2019) also states that MTurk users are typically young to middle aged adults, due to their greater technological proficiency. Studies have, however, found that data collected using MTurk samples produces results that are comparable to those found with other types of convenience samples (Jahnke, Imhoff, \& Hoyer, 2015; Shank, 2016). Although workers were able to complete HITs in time and location of their choosing, there is little evidence that 
distractions negatively impact the quality of their responses (Chandler, Mueller, \& Paolacci, 2014). Chandler, et al. (2014) utilized an experiment testing a condition where MTurk workers watched television or in the room with others while completing HITs, compared to a condition where workers only worked on completing HITs. Results showed these distractions did not impact the quality of work on the HITs. Notably, MTurk workers have an approval rating based on the percentage of past work assignments that has been approved by requestors. This approval rating impacts their reputation and approval for future HITs. This study was only advertised to workers who have completed at least 100 tasks on MTurk and have at least a 97\% approval rating, as higher approval ratings typically are associated with higher quality data (Lovett, Bajaba, Lovett, \& Simmering, 2018; Peer, et al., 2014).

While 405 participants were initially recruited to take this survey, responses from 57 participants were omitted from the sample, leaving the total population at 348. Of those that were not included in the final sample, 22 failed an attention check question ${ }^{1}$. Additionally, 35 individuals self-identified as having an opioid addiction or disorder, and one person did not indicate whether or not they had personal experience with OUD. The data from these individuals was not included in the final sample because their personal identification as persons with OUD would bias their perceptions of others with an OUD.

\footnotetext{
${ }^{1}$ Participants were given a list of topics in a multiple-choice question and asked, "which of the following topics best describes the topic of the article you read?" Answers included public transportation, a proposed treatment center, electing a new mayor, banning pit bulls, or none of Although $93.97 \%$ of the sample were able to correctly identify the topic of the article that they read, many participants did not. Sixteen incorrectly identified the topic in the opioid addict condition, and six incorrectly identified the wrong topic in the comparison condition. These participants were not included in any subsequent analysis.
} 
In terms of demographics, a total of $58 \%$ of the final sample identified as male, $41 \%$ identified as female, $0.5 \%$ identified as male-to-female transgender, and two $(0.5 \%)$ respondents did not share their gender. The ages of participants ranged from 20 to 78 years old $(M=37.15$, $S D=11.63)$. While a majority of participants identified as White/Caucasian $(n=273,78.4 \%)$, a small percentage identified as African American/Black ( $n=24,6.9 \%)$, Eastern Asian $(n=20$, 5.7\%), and Central Asian ( $n=5,1.4 \%)$. Six respondents (1.72\%) did not specify a race/ethnicity. In terms of education, thirty-nine respondents (11.2\%) indicated that their highest level of education was a high school diploma or GED, nearly a fifth of participants reported having attended some college $(n=63,18.1 \%)$, half of participants reported having a Bachelor's Degree or Associates degree $(n=185,53.2 \%)$, and $10.1 \%$ reported having earned a Master's degree $(n=35)$. The sample included respondents who resided in most U.S. states, with the exceptions of Delaware, Mississippi, Nebraska, North Dakota, Vermont, and Wyoming. Notably, a large proportion of participants reported residing in California $(n=43,12.4 \%)$. Because the Appalachian region is considered to be the heart of the opioid epidemic, participants were asked if they lived in the region of Appalachia, and 26 participants said yes (8\%). Finally, in terms of annual household income, $20.9 \%$ reported earning between $\$ 0$ and $\$ 30,000,34.8 \%$ reported earning between $\$ 30,001$ and $\$ 60,000,24.7 \%$ reported earning between $\$ 60,001$ and $\$ 90,000$, 9.7\% reported earning between $\$ 90,001$ and $\$ 120,000,5.7 \%$ reported earning between $\$ 120,001$ - $\$ 150,000$, and $4 \%$ reported earning $\$ 150,001$ or more.

\section{Procedure}

After the study was acknowledged by the IRB at West Virginia University, participants were recruited with an advertisement posted on MTurk (see Appendix A). The advertisement explained that participants in the study read an article about "a pressing social issue" and then 
gave their opinion about it. Interested participants were given a link to a Qualtrics-hosted online survey. The first page of the survey was a cover letter describing the study and respondents' rights as research participants (see Appendix B). If they agreed to participate, participants were randomly assigned to read one of three news articles. In the final sample, 113 participants were assigned to read the article that used the label of "opioid addict", 118 were assigned to read the article that used the label of "opioid use disorder," and 117 were assigned to read the comparison article about a topic completely unrelated to substance use. After reading the article, participants proceeded to complete the online questionnaire containing questions about their opinions of the article, their perceptions of people who use drugs, and demographic information. The MTurk worker participants were compensated $\$ 1.43$.

\section{Stimulus Material}

Two versions of a news article were created for the experimental stimuli in this study. The articles focus on the story of a (fictitious) community, Smithville, that is debating whether or not to permit a treatment facility for people who use opioids to open in a residential neighborhood. This article was created to resemble an online news article, written by an unnamed staff member. The article features a picture of people gathered for a town hall meeting in a high school gymnasium. Both of these articles are identical, with the exception of whether they use "people with opioid use disorder" or "people who are addicted to opioids" to label people who could benefit from treatment at the new facility. The two articles are nearly the same length. The "opioid addiction" condition consists of 521 words, the "opioid use disorder" condition consists of 537 words.

Additionally, a third news article was created which focuses on the same community of Smithville that is debating a proposal to ban certain dog breeds in the city limits, such as pit 
bulls. Participants assigned to read this article were used as a comparison group. This group will provide a baseline of people's perceptions and behaviors toward people who use drugs without having been exposed to the labels under investigation. There are no research questions or hypotheses about this condition. It will not be examined in any of the primary analyses. The purpose of this condition is to determine if either of the labels for opioid use had an effect on how participants stigmatize people with the condition. The same image that accompanies the experimental articles accompanies this one. The article was written to be similar to the experimental stimuli and it is approximate in length, with 534 words. The stimuli for all can be found in appendix $\mathrm{C}$.

\section{Measures}

The online questionnaire included attention and manipulation checks, measures of people's attitudes and feelings about people who use drugs, as well as their attitudes and behavioral intentions towards people who use drugs. Additionally, participants were surveyed about their impressions of the article's credibility, liking, quality, and representativeness, as well as their personal experience with drug use, so that these factors can be examined as control variables. Some additional measures that do not pertain directly to the hypothesis tests in this study (e.g., measures of passive facilitation behavior) were included in case they are needed for supplemental analyses. A complete list of measures that were included on the survey can be found in Appendix D. In terms of the survey, participants randomly assigned to each condition had language specific to the condition they were assigned. For example, participants in the opioid addiction condition answered questions about opioid addicts and opioid use condition participants answered questions about opioid use disorder. Participants in the comparison condition were randomly assigned to answer questions about opioid addicts or opioid use 
disorder. The following sections contain brief descriptions of the measures relevant to this current research.

Warmth. A 4-item measure of warmth was adapted from Fiske (1998). The questions inquired as to how warm, tolerant, good natured, and sincere the general public views people with opioid addiction or people with opioid use disorder. Participants were asked to respond to the questions on a seven-point scale ranging from 1 (Disagree Strongly) to 7 (Agree Strongly). The scale exhibited good internal consistency $(M=3.33, S D=1.66, \alpha=.94)$.

Competence. A 5-item measure of competence from the stereotype content model was adapted from Fiske (1998). The questions utilized asked about how competent, confident, independent, competitive, and intelligent the general public thinks people with an opioid addiction or people with opioid use disorder. Participants were asked to respond to questions on a seven-point scale ranging from 1 (Disagree Strongly) to 7 (Agree Strongly). This scale also showed good internal consistency $(M=3.14, S D=1.59, \alpha=.93)$

Contempt. A 4-item measure of contempt from the stereotype content model was adapted from Cuddy, et al. (2007). The questions utilized asked participants to assess how much contempt, anger, and disgust they feel toward people with opioid addiction or opioid use disorder. Participants were asked to indicate their feelings on a seven-point scale ranging from 1 (Disagree Strongly) to 7 (Agree Strongly). This scale was reliable $(M=4.84, S D=1.44, \alpha=.87$ )

Pity. A 4-item measure of pity from the stereotype content model was adapted from Cuddy, et al. (2007). The questions inquired about how much participants feel pity, sympathy, sorry for, and concern toward people with opioid addiction or opioid use disorder. Participants were asked to respond to questions how they generally feel on a seven-point scale ranging from 1 
(Disagree Strongly) to 7 (Agree Strongly). This scale was also internally consistent $(M=4.94$, $S D=1.18, \alpha=.83)$

Active Facilitation Behaviors. A 6-item measure of active harm behavior was created for this study. Items were designed to tap into participants' perceptions of behaviors that are related to the proposal to build a treatment facility as discussed in the experimental articles. Participants were asked to indicate how supportive they think others would be of proposals to help people who use drugs on a seven-point scale ranging from 1 (Not At All Supportive) to 7 (Extremely Supportive). Specifically, they were asked how supportive others would be of proposals to build a treatment facility in their community, allocate tax dollars to support treatment programs, create clean needle exchange programs, donating money to support treatment programs, donating money to keep users sober, as well as volunteer time at treatment centers. This scale showed good internal consistency $(M=4.59, S D=1.44, \alpha=.83 .8)$. Notably, the scale was positively correlated with Cuddy et al.'s (2007) more general scale of active facilitation, $r=.26, p<.001$.

Active Harm Behaviors. A 5-item measure of active harm behaviors $(M=3.05$, $S D=1.56, \alpha=.88)$ was created for this study. Participants were asked to indicate how supportive they think others would of penalizing drug users in certain ways, using a scale of 1 (Not At All Supportive) to 7 (Extremely Supportive). Specifically, participants were asked to indicate how supportive they think others would be of legislation to increase incarceration time for crimes committed by drug users, increase incarceration time for people convicted of using drugs, relocate of drug users to other communities, decrease government programming designed to benefit drug users, and make it harder for users to get jobs. Both the active facilitation and active harm items were distributed in random order and they were embedded among questions about other types of behaviors related to other community-issues (e.g., speed bumps, breed- 
specific legislation, homelessness). This scale was reliable $(M=3.05, S D=1.56, \alpha=.88)$, positively correlated with Cuddy et al.'s (2007) more general measure of active harm, $r=.11$, $p=.03$.

Control variables. There were seven variables that were used as control variables: personal experience with substance use disorders, perceptions of community impact, income, education, age, and effort spent taking the survey.

Personal experience with substance use disorders. Personal experience with substance use disorders (including, but not limited to opioid use disorder), whether it is personally having the substance use disorder or having a close friend or family member with a substance use disorder, should affect the stereotypes, emotions, and behavioral intentions people have toward other people with substance use disorders. Therefore, this variable was used as a control variable. To measure personal experience with substance use disorder, participants were asked whether they or someone close to them has a substance use disorder. For analyses, participants will be classified by whether they have personal experience with substance use disorders (1) or not (0).

Perceptions of Community Impact. The extent to which people feel like they personally have been affected by the opioid crisis Perceptions of impact from opioid use on one's community and personal feelings could affect how participants interpret the article about how another community is dealing with the opioid crisis. Therefore, this variable was used as a control variable. To measure perceptions of impact, participants were asked about their perceived percentage of people who have an opioid use disorder in their community. Participants then answered how much they feel they have been personally negatively affected, how much their friends and acquaintances have been negative affected, and how much the people in their community in general have been negatively impacted by the opioid crisis. Finally, participants 
were asked to respond to questions about negative impacts to community economy, physical health in the community, mental health in the community, safety, and well-being of children and families.

Income. According to Fiske (1998), income can impact stereotype perceptions of individuals. Individuals who have low income levels are thought to have lower competence, and warmth is decreased if there is the perception that individuals also use government assistance. Because of these stereotypes, behavioral tendencies are also impacted. The BIAS Map argues that those who have a more stable income tend to distance themselves from those with lower income levels and judge low income individuals, and stigmatized groups in general, as less than (Cuddy, et al., 2007). Because of this idea that those with higher incomes might judge stigmatized groups more than lower incomes, income level will be used as a control variable.

Education. Similar to income levels, participants were also asked to report their highest level of education obtained, as a control variable. The BIAS Map argues that individuals who are more educated have more intelligence, confidence, independence capabilities, and are therefore thought to be more aware of their own stereotypes (Cuddy, et al., 2007). MTurk workers typically have a higher educational achievement, with a mean education level of a Bachelor's degree, this can impact the level of awareness participants have toward their own biases toward individuals who use opioids (McDuffie, 2019; Ross, Irani, Silberman, Zalvidar, \& Tomlinson, 2010).

Age. Janmaat and Keating (2019) found that adolescents and young adults show more tolerant attitudes towards marginalized and discriminated against groups. The study involved participants responding to stigmatized groups, such as racial groups, immigrants, and members of the LGBTQ+ community. The data suggests that over time, all groups (e.g., ages 15-29, 30- 
$49,50+$ ) have become more tolerant of stigmatized groups. However, participants in the group aged 50 or older were significantly less tolerant of the stigmatized groups (Janmaat \& Keating, 2019). Because age plays a significant role in tolerance, treatment, and discrimination, age was used as a control variable for this study.

Effort. According to Zamarro (2018), measuring the amount of effort put into taking a survey can indicate how much attention participants were paying. Hauser, Paolacci, and Chandler (2019) argued that it is important to control for effort put into taking a survey as it can skew results due to negligence. Participants who put little effort into taking surveys miss important details or provide trivial responses can skew true relationships between variables. Hauser, et al. (2019) also stated that little effort put into taking the survey can increase systematic error. Issues with low effort and "straight-lining" (e.g., selecting the same option for all statements within a single measurement) can create appearance of consistency, but lead to false positives in the results. Because effort can lead to skewed relationships and false positives in results, it was used as a control variable. 


\section{CHAPTER III}

\section{Results}

\section{Descriptive and Preliminary Analyses}

Correlations. Although this study did not make specific predictions about all of the key variables in the BIAS Map (e.g., admiration and envy), they were measured in the interest of gaining a more complete picture of how these variables relate to the variables of in interest in the current study. ${ }^{2}$ Likewise, in terms of behavioral intentions, although only this study is primarily interested in understanding how labels affect active facilitation and active harm, measures of passive facilitation and passive harm were also taken for the sake of comparison. In addition to the applied measures of active facilitation and active harm created for this research, Cuddy et al.'s (2007) original, more general measures of active facilitation and active harm were also included in the survey. ${ }^{3}$ Table 2 displays the zero-order correlations between the variables. Consistent with the BIAS Map, warmth was positively correlated with competence $(r=.88$, $p<.001)$, pity $(r=.14, p=.008)$, admiration $(r=.65, p<.001)$, and envy $(r=.54, p<.001)$, but negatively associated with contempt $(r=-.39, p<.001)$. Competence was positively associated

\footnotetext{
${ }^{2}$ Admiration and envy were also examined in exploratory analyses, as original variables from Cuddy, et al. (2007). Admiration $(M=2.20, S D=1.61, \alpha=.89)$ was a two-item measure that stated that the general public feels admiration, and pride toward this group. Envy $(M=1.96$, $S D=1.49, \alpha=.86$ ) was a two-item measure that stated that the general public feels envy, and jealousy toward this group.

${ }^{3}$ The original behavioral scales; active facilitation, passive facilitation, active harm, and passive harm were also examined in this study. Active facilitation was a two-item measure that stated that the general public would help, and protect this group $(M=4.19, S D=1.42, r=.54$, $p<.001)$. Passive facilitation was a two-item measure that stated that the general public would cooperate, and associate with this group $(M=3.04, S D=1.57, r=.65, p<.001)$. Active harm was a two-item measure that stated that the general public would fight and attack this group $(M=3.59, S D=1.68, r=.63, p<.001)$. Passive harm was a two-item measure that stated that the general public would exclude, and demean this group $(M=4.47, S D=1.65, r=.66$, $p<.001)$.
} 
with pity $(r=.11, p=.04)$, admiration $(r=.69, p<.001)$, and envy $(r=.60, p<.001)$, and negatively associated with contempt $(r=-.35, p<.001)$. Contempt was also negatively associated with admiration $(r=-.20, p<.001)$, but unrelated to pity or envy. Pity was positively associated with admiration $(r=.11, p=.047)$. Finally, admiration was positively associated with envy $(r=.81, p<.001)$.

In terms of behavioral intentions, the applied active facilitation measure created for this study was positively correlated with warmth $(r=.31, p<.001)$, competence $(r=.33, p<.001)$, pity $(r=.18, p<.001)$, envy $(r=.19, p<.001)$, and admiration $(r=.22, p<.001)$. The applied measure of active facilitation was also positively correlated with Cuddy et al.'s (2007) original scale for passive facilitation $(r=.27, p<.001)$, active harm scale $(r=.16, p<.001)$. and the original measure active facilitation $(r=.26, p<.001)$. The applied measure of active harm was positively correlated with warmth $(r=.28, p<.001)$, competence $(r=.36, p<.001)$, admiration $(r=.55, p<.001)$ and envy $(r=.56, p<.001)$. Applied active harm was also positively correlated with the original measure for passive facilitation $(r=.43, p<.001)$, the original measure of active facilitation $(r=.24, p<.001)$ and the original measure for active harm $(r=.12, p=.04)$

Comparison group analyses. A MANOVA was conducted to explore how the two experimental conditions differentially affected participants' perceptions of people with OUD compared to the comparison group, which provided a baseline of people's perceptions. The dependent variables entered in this analysis were as follows: warmth, competence, contempt, pity, admiration, envy, passive facilitation, passive harm, as well as active facilitation and active harm (both the scale created for this study and Cuddy, et al.'s (2007) original scale). Interpersonal experience with OUD, age, income, education, and survey effort were entered as 
covariates. ${ }^{4}$ The results of this analysis did not reveal any significant differences between the three conditions and the dependent variables at the level of $p<.01$. The multivariate test of the differences among the three labels was not significant, Wilks' $\lambda=.93, F(24,658)=1.00$, partial $\eta^{2}=.04, p=.44$. However, at the more liberal threshold of statistical significance, $p<.05$, some differences in competence $F(2,340)=2.89, p=.06$, partial $\eta^{2}=.02$, contempt, $F(2,340)=4.67, p=.09$, partial $\left.\eta^{2}=.01\right)$, and passive facilitation, $F(2,340)=2.83, p=.06$, partial $\eta^{2}=.02$, emerged. Fisher's LSD post-hoc analyses revealed that, surprisingly, when compared to the comparison condition $(M=2.85, S E=.14)$, the addict label resulted in higher perceptions of competence $(M=3.32, S E=.15, p=.024)$. There was no difference in perceptions of competence between the OUD label $(M=3.23, S E=.14)$ and the other two groups. Similarly, the findings also revealed the addict label resulted in less contempt $(M=4.60$, $S E=.13, p=.066)$ than the comparison condition $(M=4.94, S E=.13)$. Once again, perceptions of contempt for those exposed to the OUD label $(M=4.96, S E=.13)$ did not differ from the other conditions. Finally, the results revealed that compared to the comparison condition $(M=2.79, S E=.14)$, participants in the addict condition expressed greater support for applied passive facilitation $(M=3.27, S E=.15, p=.02)$. Respondents in the disorder group did not express any more or any less support for passive facilitation than those in the other two groups $(M=3.08, S E=.14)$

\footnotetext{
${ }^{4}$ Participants' race and gender were entered as control variables in a prior version of the model but because these variables did not have a significant relationship with any variables of interest they were not included in the current analysis.
} 
Table 1. Mean Comparisons Across Experimental Conditions

\begin{tabular}{lccccccccc}
\hline & $\begin{array}{c}\text { Comparison } \\
\text { Condition } \\
(n=117)\end{array}$ & $\begin{array}{c}\text { Addiction } \\
\text { Condition } \\
(n=113)\end{array}$ & $\begin{array}{c}\text { Disorder } \\
\text { Condition } \\
(n=118)\end{array}$ & & & \\
& $M$ & $S D$ & $M$ & $S D$ & $M$ & $S D$ & $F$ & $p$ & $\begin{array}{c}\text { Partial } \\
\eta^{2}\end{array}$ \\
\hline \multicolumn{1}{c}{ Variable } & $3.11_{\mathrm{a}}$ & 1.57 & $3.51_{\mathrm{a}}$ & 1.60 & $3.36_{\mathrm{a}}$ & 1.80 & 1.79 & .173 & .010 \\
\hline Warmth & $2.85_{\mathrm{a}}$ & 1.48 & $2.32_{\mathrm{b}}$ & 1.54 & $3.24_{\mathrm{a}, \mathrm{b}}$ & 1.71 & 2.89 & .057 & .020 \\
Competence & $4.86_{\mathrm{a}}$ & 1.11 & $4.96_{\mathrm{a}}$ & 1.17 & $4.98_{\mathrm{a}}$ & 1.27 & 0.22 & .800 & .001 \\
Pity & $4.94_{\mathrm{b}}$ & 1.29 & $4.60_{\mathrm{a}}$ & 1.46 & $4.69_{\mathrm{a}, \mathrm{b}}$ & 1.56 & 2.36 & .096 & .010 \\
Contempt & $1.83_{\mathrm{a}}$ & 1.34 & $2.17_{\mathrm{a}}$ & 1.58 & $1.90_{\mathrm{a}}$ & 1.54 & 1.44 & .240 & .008 \\
Envy & $1.96_{\mathrm{a}}$ & 1.47 & $2.38_{\mathrm{a}}$ & 1.66 & $2.26_{\mathrm{a}}$ & 1.69 & 1.61 & .200 & .009 \\
Admiration & $4.55_{\mathrm{a}}$ & 1.58 & $4.37_{\mathrm{a}}$ & 1.67 & $4.49_{\mathrm{a}}$ & 1.70 & 0.35 & .710 & .002 \\
Passive Harm & $2.77_{\mathrm{b}}$ & 1.47 & $3.27 \mathrm{a}$ & 1.49 & $3.10_{\mathrm{a}, \mathrm{b}}$ & 1.70 & 2.83 & .060 & .020 \\
Passive Facilitation & $3.53_{\mathrm{a}}$ & 1.68 & $3.63_{\mathrm{a}}$ & 1.64 & $3.63_{\mathrm{a}}$ & 1.75 & 0.09 & .920 & .001 \\
Active Harm & $4.03_{\mathrm{a}}$ & 1.35 & $4.34_{\mathrm{a}}$ & 1.32 & $4.20_{\mathrm{a}}$ & 1.56 & 0.96 & .390 & .006 \\
Active Facilitation & $2.82_{\mathrm{a}}$ & 1.44 & $3.20_{\mathrm{a}}$ & 1.56 & $3.12_{\mathrm{a}}$ & 1.65 & 1.65 & .190 & .010 \\
Applied Active Harm & $4.43_{\mathrm{a}}$ & 1.43 & $4.59_{\mathrm{a}}$ & 1.49 & $4.77_{\mathrm{a}}$ & 1.49 & 1.53 & .22 & .009 \\
Applied Active Facilitation & & & & & & & & & \\
\hline
\end{tabular}

Note. Means in each row that do not differ significantly per a Fisher's LSD post-hoc test, $\mathrm{p}<.10$, share a common subscript.

\section{Hypotheses Tests}

Hypothesis 1 predicted that compared to the label "addiction," the label "disorder" will elicit perceptions of higher warmth. To address H1, an independent samples t-test was conducted comparing participants' how perceptions of warmth (DV) varied between the two experimental labels, "addict" versus "disorder." There was not a significant difference in the scores for the 
labels "addict" $(M=3.51, S D=1.59)$ and "opioid use disorder" $(M=3.36, S D=1.80)$ and warmth; $t(229)=.67, p=.50$. Thus, hypothesis one was not supported.

Hypothesis 2 predicted that compared to the label "addict," the label "disorder" will elicit greater perceptions of pity. To address $\mathrm{H} 2$, an independent samples t-test was conducted comparing participants assigned to the two experiment label conditions in terms of pity. There was not a significant difference in pity felt for a people with an addiction $(M=4.96$, $S D=1.17)$ compared to a disorder $(M=4.98, S D=1.27)$ and pity; $t(229)=-.12, p=.90$. Thus, hypothesis two was not supported.

Hypothesis 3 predicted that compared to the label "addict," the label "disorder" would elicit less perceptions of contempt. Once again, an independent samples t-test was conducted comparing participants assigned to the two label conditions in terms of the level of contempt they elicited. In this case, contrary to predictions, the "addict" label resulted in slightly lower feelings of contempt $(M=4.60, S D=1.46)$ than the "disorder" label $(M=4.96, S D=1.56)$, although this difference was not significant at the traditional threshold for statistical significance $t(229)=-1.82, p=.07$. Thus, hypothesis two was not supported.

Hypothesis 4 predicted that there is an indirect effect of the label for "disorder" on active harm behaviors through increased warmth and decreased contempt. The hypothesis was tested through a serial mediation analysis using the PROCESS macro v3.4 for SPSS (Hayes, 2018). 
Table 2. Zero-Order Correlation Matrix

\begin{tabular}{|c|c|c|c|c|c|c|c|c|c|c|c|c|c|c|}
\hline Variables & $M$ & $S D$ & 1 & 2 & 3 & 4 & 5 & 6 & 7 & 8 & 9 & 10 & 11 & 12 \\
\hline 1. Warmth & 3.33 & 1.66 & -- & & & & & & & & & & & \\
\hline 2. Competence & 3.14 & 1.59 & $.88^{* * *}$ & -- & & & & & & & & & & \\
\hline 3. Contempt & 4.84 & 1.44 & $-.39 * * *$ & $-.35 * * *$ & -- & & & & & & & & & \\
\hline 4. Pity & 4.94 & 1.18 & $.14 * *$ & $.11 *$ & -.02 & -- & & & & & & & & \\
\hline 5. Admiration & 2.20 & 1.61 & $.65^{* * *}$ & $.69 * * *$ & $-.20 * * *$ & $.11^{*}$ & -- & & & & & & & \\
\hline 6. Envy & 1.96 & 1.49 & $.54 * * *$ & $.60 * * *$ & .00 & .09 & $.81 * *$ & -- & & & & & & \\
\hline $\begin{array}{l}\text { 7. Passive } \\
\text { Facilitation }\end{array}$ & 3.04 & 1.57 & $.67 * * *$ & $.68 * * *$ & $-.28 * *$ & $.20 * * *$ & $.74 * *$ & $.62 * *$ & -- & & & & & \\
\hline 8. Passive Harm & 4.47 & 1.65 & $-.26 * * *$ & $-.20 * * *$ & $.59 * *$ & -.06 & $-.13^{*}$ & .05 & $-.32 * *$ & -- & & & & \\
\hline $\begin{array}{l}\text { 9. Active } \\
\text { Facilitation }\end{array}$ & 4.19 & 1.41 & $.50 * * *$ & $.48 * * *$ & $-.24 * * *$ & $.43 * * *$ & $.42 * *$ & $.33 * *$ & $.67 * *$ & -.35 & -- & & & \\
\hline 10. Active Harm & 3.59 & 1.68 & -.04 & .01 & $.49 * * *$ & .06 & .10 & $.27 * * *$ & -.05 & $.68 * * *$ & $-.17 * *$ & -- & & \\
\hline $\begin{array}{l}\text { 11. Applied Active } \\
\text { Facilitation }\end{array}$ & 4.68 & 1.42 & $.31 * * *$ & $.33 * * *$ & .01 & $.18 * *$ & $.22 * * *$ & $.19 * *$ & $.27 * *$ & $.08 * *$ & $.26^{* * *}$ & $.16^{* *}$ & -- & \\
\hline $\begin{array}{l}\text { 12. Applied Active } \\
\text { Harm }\end{array}$ & 3.05 & 1.56 & $.28 * * *$ & $.36^{* * *}$ & -.03 & .07 & $.55^{* *}$ & $.56^{* *}$ & $-.43 *$ & -.08 & $.24 * *$ & $.11^{*}$ & $-.12 *$ & -- \\
\hline
\end{tabular}

Note. ${ }^{*} p<.05,{ }^{* *} p<.01,{ }^{* * *} p<.001$ 
Specifically, PROCESS Model 6 was used with 95\% confidence intervals and 5,000 bootstrapped samples. The experimental condition was entered as the independent variable (X), with the addiction condition coded as 0 . Warmth (M1) and contempt (M2) were entered as serial mediators, and the applied measure of active harm $(\mathrm{Y})$ was entered as the dependent variable. Five control variables were included: interpersonal experience with substance use disorders, age, income, education, and effort put into taking the survey.

Figure 4 displays an illustration of the model results. Results of this analysis showed there was not a direct effect of the labels on active harm $\left(c^{\prime}=-.08, p=.71,95 \%\right.$ CI: $\left.-.48, .33\right)$. There also was not an indirect effect of the label on active harm through warmth $\left(a_{1} b_{2}=-.05,95 \%\right.$ CI: $-.19, .05)$. Similarly, the indirect effect of the label on active harm through contempt was not significant $\left(a_{2} b_{1}=.04,95 \%\right.$ CI: -.02, .12). Finally, the predicted serial mediation effect of the label on active harm through warmth and then contempt was not significant $\left(a_{1} a_{3} b_{1}=.01,95 \% \mathrm{CI}\right.$ : -.01 , $.04)$. Thus, hypothesis four was not supported. Table 2 contains a list of the tested indirect effects. A complete list of the model's ordinary least squares coefficients is listed in Table 3.

Figure 4. Coefficients Path Model for Hypothesis 4

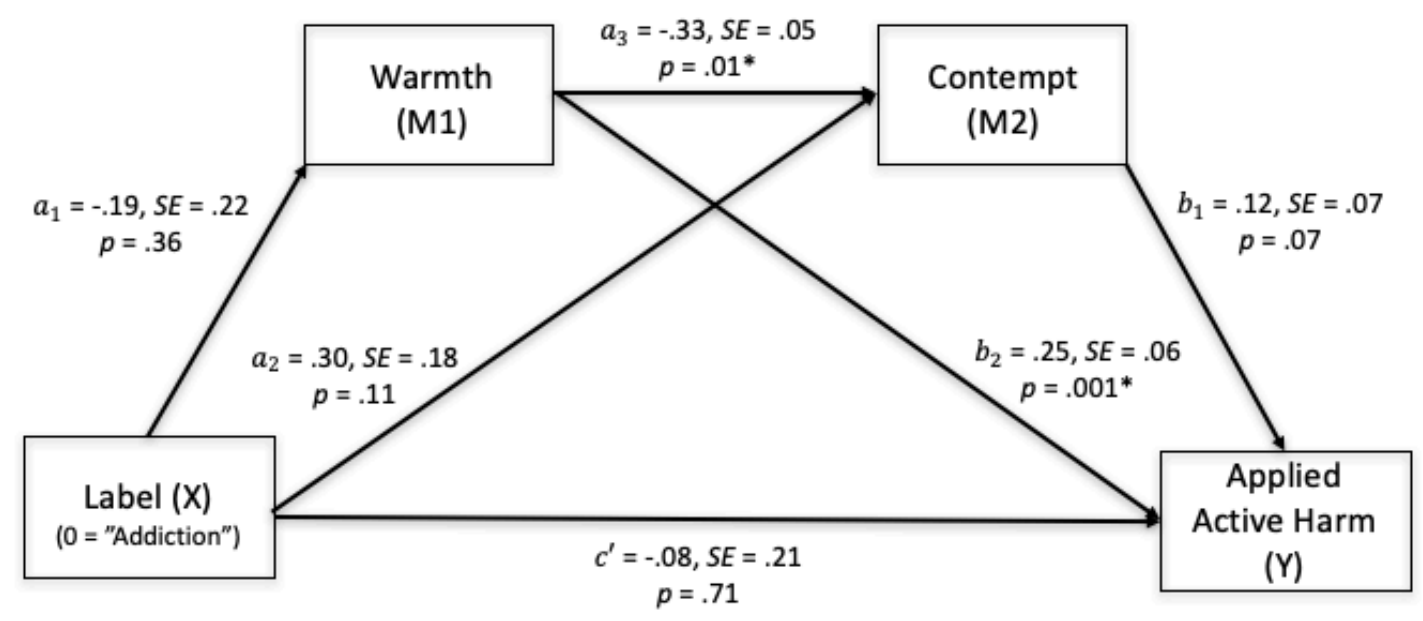

Note. * indicates a statistically significant relationship 
Table 3. Indirect Effects Path Model Coefficients

\begin{tabular}{lcccc}
\hline \multicolumn{1}{c}{ Indirect Effect } & Coefficient & SE & LLCI & ULCI \\
\hline Total Effect & -.01 & .06 & -.14 & .12 \\
Label $\rightarrow$ Warmth $\rightarrow$ Active Harm & .05 & .06 & -.19 & .06 \\
Label $\rightarrow$ Contempt $\rightarrow$ Active Harm & .04 & .04 & -.02 & .12 \\
Label $\rightarrow$ Warmth $\rightarrow$ Contempt $\rightarrow$ Active Harm & .01 & .01 & -.01 & .04 \\
\hline
\end{tabular}

Note. Relative indirect effects are unstandardized

Table 4. OLS Path Model Coefficients

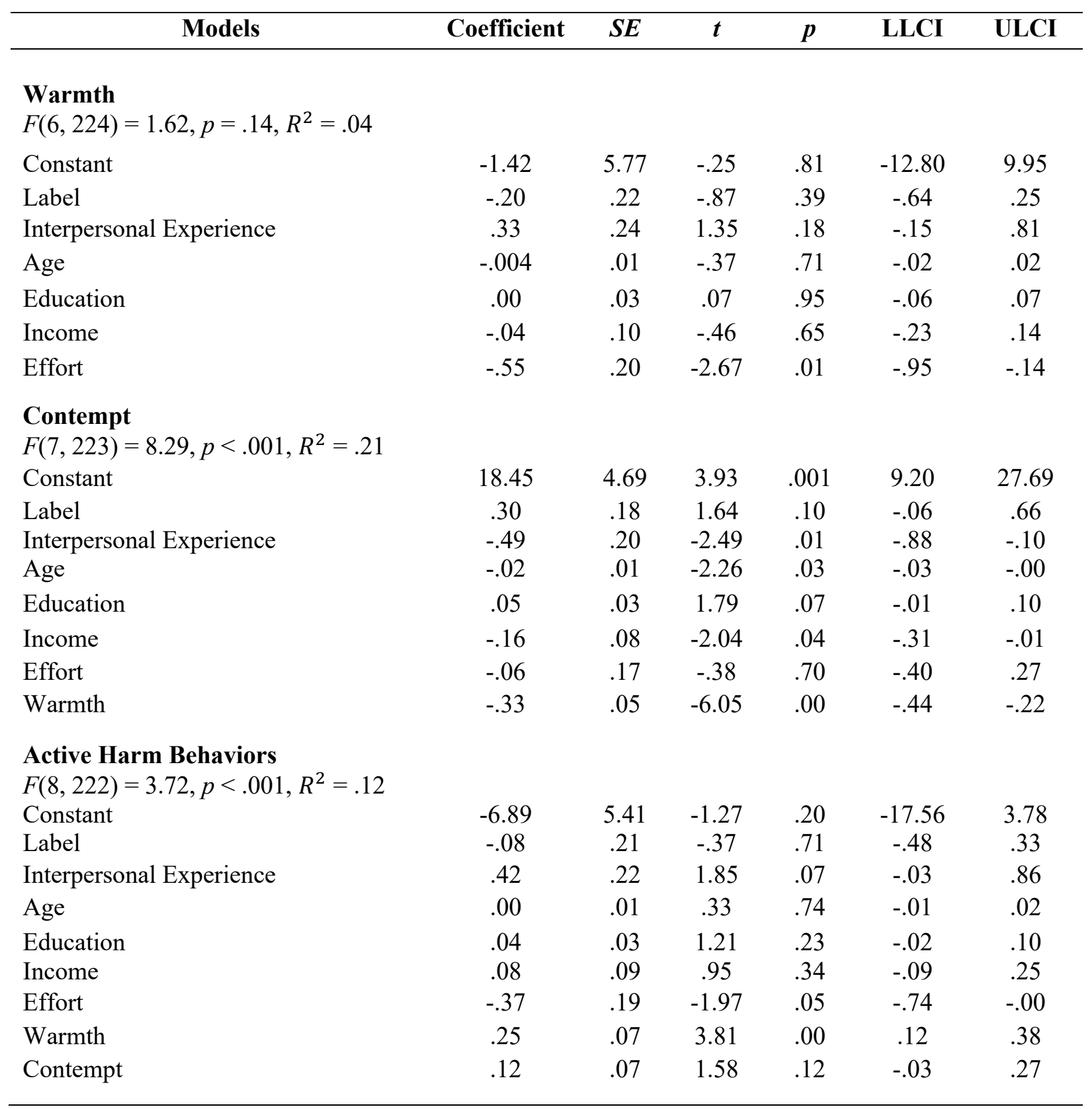

Note. Direct effects are unstandardized 
Hypothesis 5 predicted that would be an indirect effect of the label for "disorder" on active facilitation behaviors through increased warmth and increased pity. Once again, this hypothesis was tested using PROCESS model 6 with 95\% confidence intervals and 5,000 bootstrap samples. The model was identical to the model used to test H4, except that pity was entered as the second mediator (M2), and active facilitation (Y) was entered as the dependent variable. The direct effect of the label on active facilitation was not significant $\left(c^{\prime}=.19, p=.29\right.$, $95 \%$ CI: $-.17, .55)$. The results also showed that the indirect effect of the label on active facilitation through warmth was not significant $\left(a_{1} b_{2}=-.05,95 \%\right.$ CI: -.17, .06). Similarly, the indirect effect of the label on active facilitation through pity was not significant $\left(a_{2} b_{1}=.01,95 \%\right.$ CI: -.06, .09). Finally, contrary to the prediction, the serial indirect effect of the label on active facilitation through warmth and then pity was not significant $\left(a_{1} a_{3} b_{1}=-.004,95 \% \mathrm{CI}:-.02, .01\right)$. Thus, hypothesis five was not supported. Table 4 contains a list of the tested indirect effects. A complete list of the model's ordinary least squares coefficients is listed in Table 5. Figure 5 displays an illustration of the model results.

Figure 5. Coefficients Path Model for Hypothesis 5

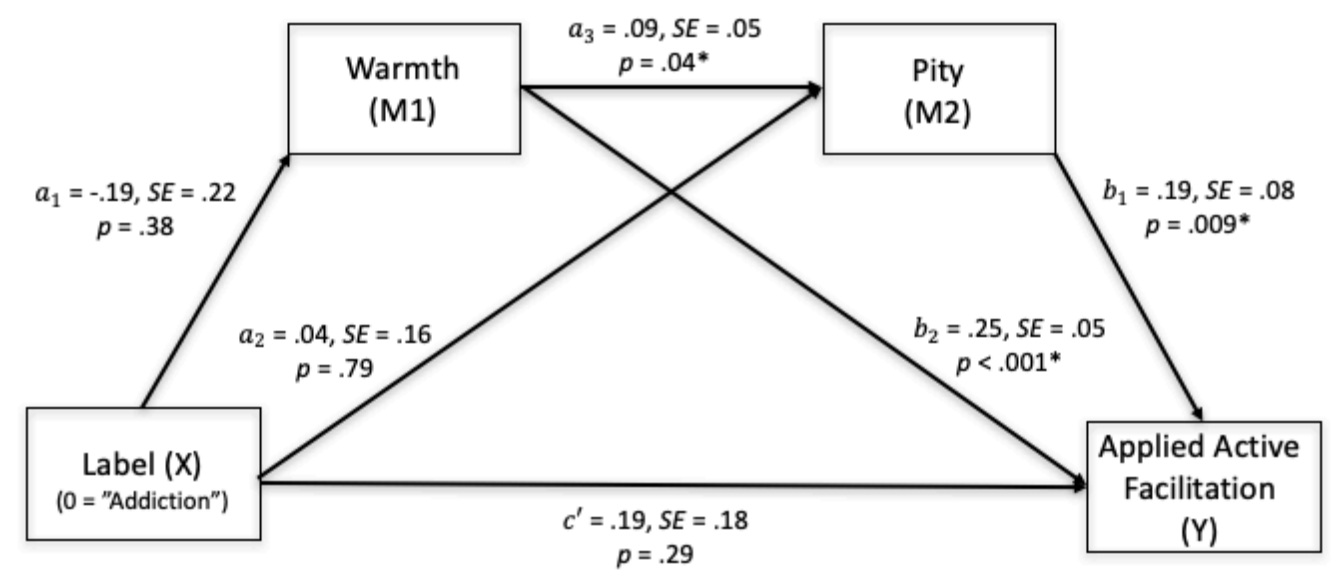

Note. * indicates a statistically significant relationship 
Table 5. Indirect Effects Path Model Coefficients

\begin{tabular}{lcccc}
\hline \multicolumn{1}{c}{ Indirect Effect } & Coefficient & SE & LLCI & ULCI \\
\hline Total Effect & -.05 & .07 & -.19 & .09 \\
Label $\rightarrow$ Warmth $\rightarrow$ Active Facilitation & -.05 & .06 & -.17 & .06 \\
Label $\rightarrow$ Pity $\rightarrow$ Active Facilitation & .01 & .04 & -.05 & .09 \\
Label $\rightarrow$ Warmth $\rightarrow$ Pity $\rightarrow$ Active Facilitation & .003 & .01 & -.02 & .01 \\
\hline
\end{tabular}

Note. Relative indirect effects are unstandardized

Table 6. OLS Path Model Coefficients

\begin{tabular}{lllllll} 
Models & Coefficient & $S E$ & $t$ & $p$ & LLCI & ULCI \\
\hline
\end{tabular}

\section{Warmth}

$F(6,224)=1.62, p=.14, R^{2}=.04$

Label

Interpersonal Experience

Age

Education

Income

Effort

$\begin{array}{lccccc}-1.42 & 5.77 & -.25 & .81 & -12.80 & 9.95 \\ -.20 & .22 & -.87 & .39 & -.64 & .25 \\ .33 & .24 & 1.35 & .18 & -.15 & .81 \\ -.004 & .01 & -.37 & .71 & -.02 & .02 \\ .00 & .03 & .07 & .95 & -.07 & .07 \\ -.04 & .10 & -.46 & .65 & -.23 & .14 \\ -.55 & .20 & -2.67 & .01 & -.95 & -.14\end{array}$

Pity

$F(7,223)=1.09, p=.37, R^{2}=.03$

Constant

Label

Interpersonal Experience

Age

Education

Income

Effort

Warmth

$\begin{array}{lccccc}4.78 & 4.15 & 1.15 & .25 & -3.40 & 12.95 \\ .04 & .16 & .26 & .79 & -.28 & .36 \\ .02 & .18 & .09 & .93 & -.33 & .36 \\ .00 & .01 & .64 & .52 & -.01 & .02 \\ .02 & .02 & .70 & .48 & -.03 & .07 \\ .01 & .07 & .20 & .84 & -.12 & .15 \\ -.18 & .15 & -1.20 & .23 & -.47 & .11 \\ .10 & .05 & 1.98 & .05 & .000 & .19\end{array}$

\section{Active Facilitation Behaviors}

\begin{tabular}{lcccccc}
$F(8,222)=5.55, p<.001, R^{2}=.17$ & & & & & & \\
Constant & 2.84 & 3.86 & .74 & .46 & -4.76 & 10.44 \\
Label & -.03 & .15 & -.22 & .83 & -.33 & .26 \\
Interpersonal Experience & -.10 & .16 & -.62 & .54 & -.42 & .22 \\
Age & .01 & .01 & 1.15 & .25 & -.01 & .02 \\
Education & .02 & .02 & .67 & .51 & -.03 & .06 \\
Income & .15 & .06 & 2.32 & .02 & .02 & .27 \\
Effort & -.04 & .14 & -.32 & .75 & -.32 & .23 \\
Warmth & .26 & .5 & 4.73 & .00 & .15 & .36 \\
Pity & .20 & .08 & 2.64 & .01 & .05 & .35 \\
\hline
\end{tabular}

Note. Direct effects are unstandardized 


\section{CHAPTER IV}

\section{Discussion}

Besides the physical ailments that accompany OUD, sufferers are also plagued with social stigma, viewed as being dangerous, erratic, poor decision makers, self-destructive, uneducated, and sneaky among other stereotypes (Corrigan, et al., 2001; Crandall \& Reser, 2005; Nieweglowski, et al., 2017; Mushtaq, et al., 2015; Yang, et al., 2017). The alienation that results from this stigma can be devastating for people with opioid use disorder. The stigma of OUD is psychologically damaging, socially isolating (Foster, 2017), and detrimental to recovery (Matthews et al., 2017). Because they make it easier for people to categorize people into different social groups, the labels people use to describe people with OUD are thought to carry and reinforce the social stigma attached to the group (CSAT, 2016; Oakes, 2003). Research has shown that applying the label "addict" to people can make them seem more blameworthy, less deserving of help, and more worthy of avoidance (e.g., Corrigan et al., 2009). Saying that someone has an "opioid use disorder," on the other hand, has been shown to be associated with a greater perception that a person needs treatment, and relatively greater perceptions that they are not blameworthy and more deserving of sympathy and help (e.g., Kelly et al., 2010). This study sought to apply the BIAS Map (Cuddy et al., 2007) to understand how these labels influence people's behavioral intentions by activating different stereotypes and emotions. Specifically, this study argued that people labeled "addicts" would be stereotyped as being relatively low in warmth (because they are perceived as threatening; Nieweglowski et al., 2019) and low in competence (because they are perceived as unreliable; Nieweglowski et al., 2019). "Addicts" therefore were expected to elicit greater contempt and active harm behavioral intentions. But 
people labeled as having a "disorder" were expected to elicit higher perceptions of warmth, greater perceptions of pity, and lead to greater intentions to engage in active facilitation.

Neither of the two predicted models were confirmed by this research. The two label conditions did not differentially affect perceptions of warmth, pity, contempt, active facilitation, or active harm. From these findings, one might be tempted to conclude that the labels "addict" and "disorder" do not have different effects people's stereotypes, emotions, and discrimination. However, there is some reason to believe that the reason the labels did not have the predicted effects is because other aspects of the stimuli articles exerted a greater influence on people's perceptions.

One aspect of the article that could have exerted a greater influence on people's perceptions of people with OUD is the acknowledgement that they are "people." Unexpectedly, the results of this study showed that the label "opioid addict" is, perhaps, not as stigmatizing as other research has suggested (e.g., Corrigan et al., 2009). In fact, compared to a comparison condition which reflected people's baseline perceptions, the label, "addict" appears to have slightly improved people's baseline perceptions of competence, reduced feelings of contempt toward the group in question, and increased willingness to engage in passive facilitation. In hindsight, it is suspected that the reason that participants in the "addiction" label condition had slightly higher perceptions of competence and slightly reduced feelings of contempt is because the articles used person-first language (PFL). PFL is terminology that brings a focus on the person rather the diagnosis (Collier, 2012; CSAT, 2004). It is a way of stating that a person's identity is separate from any disorder or illness they have. A disorder is something they have, not something that they are (NCBDDD, 2017). 
The use of PFL became more common after the passage of the Americans With Disabilities Act of 1990, and over time, several major psychology and health organizations have supported and advocated for the adoption of PFL for the discussion of disability-related issues (Crocker \& Smith, 2019; Granello \& Gibbs, 2016 Wehmeyer, Bersani, \& Gagne, 2000). For instance, in 2009, the campaign "Spread the Word to End the Word" and legislature by congress to remove non-person-first language from government documents have made strides to focus on PFL (Congress Public Law, 2010; Crocker \& Smith, 2019). Similarly, the $7^{\text {th }}$ edition of the American Psychological Association Publication Manual advises that person-first language should be used whenever possible when writing about topics such as age, disability, gender, race, and sexual orientation (APA, 2020). Research too, indicates that PFL is, in fact, preferable to non-PFL labels for reducing prejudice. Granello and Gibbs (2016) conducted experiments with separate samples of undergraduate students, general adults, and professional counselors to determine how they responded to the PFL terminology, "people with mental illness" versus "the mentally ill." They found that all three samples expressed increase levels of tolerance in the PFL condition.

Notably, in both experimental conditions in the current study, the articles used PFL, referring to "people who have an opioid addiction," and "people who have an opioid use disorder." By emphasizing the individuality of the people discussed in the articles and detaching them from the stigmatizing category of "addicts," this language appears to have increased the perceptions of competence and reduced feelings of contempt associated with this group. Presumably, the PFL made it more difficult for people to lump people into one group and categorize them and thereby take away some of their humanity as an individual (Oakes, 2003). This could explain why, compared to the comparison group, at least, participants in the "addict" 
group had relatively more positive perceptions and behavioral intentions. Of course, this is a speculative explanation for the findings. An experiment designed to compare the effects of PFL used with opioid "addicts" and the lack of PFL would help establish whether PFL can, in fact negate any negative effects of a relatively negative label.

The reason that PFL has the effect of individuating people is because it breaks up people's tendencies to categorize others. According to Oakes (2003), the categorization process occurs when people mentally lump a person into a group of other people with shared characteristics. This is a cognitive short-cut that people use to make sense of other people. These groupings convey meanings which are not always positive (e.g., addicts are impulsive), and this can lead to discrimination. PFL should disrupt this categorization process by bringing people's focus on the person as an individual, rather than the general characteristics that they share with a group category.

As some evidence that participants in this study may have been more inclined to see "addicts" as individual "people" rather than simply members of a group, it is worth noting that many of the correlations that emerged between the variables were less consistent with intergroup perceptions and more consistent with interpersonal perceptions. According to Russell and Fiske (2008), correlations in intergroup research between warmth and competence are negatively correlated. That is, when people are making judgements about people who they have categorized as belonging to some group, the more warm they perceive the group as being, the less competent they are seen as being (and vice versa). As a group, for instance, older adults tend to be perceived as being high in warmth and low in competence. One positive perception (i.e., warmth) does not necessarily beget another positive perception (i.e., competence). But the same pattern does not tend to hold for when people's interpersonal assessments. Consistent with the 
halo effect (e.g., Forgas, 2011; Murphy, Jako, \& Anhalt, 1993), when people make one positive assessment of a person, they tend to associate them with other positive characteristics. Thus, when asked to evaluate individuals (as opposed to groups of people), warmth and competence tend to be positively correlated. Notably, in the current study, there was a positive correlation between warmth and competence, in line with interpersonal impression formation trendancies. This suggests that when asked to evaluate "people with opioid addiction" or "people with opioid use disorder" participants were likely not thinking about them as much in terms of a general group category, as much as they were perceiving them as individuals - as people.

It's not clear why the positive effect of the PFL did not extend to participants in the “disorder" condition, however. It appears that even PFL may not be strong enough to overcome potentially negative effects of a "disorder" label. Why might the term "disorder" have been more immune to the positive effects of PFL? Perhaps the term disorder conjures negative associations such as abnormality, sickliness, weakness, powerlessness, and dependence. As a result, they may be seen as still lacking competence even if they are people who are suffering from a disorder. On the other hand, there may be something unique about the term "addict" that, although not entirely positive, is at least better understood by the public than "disorder." Perhaps the PFL only reduced contempt towards people who are addicts instead of people with disorders because people are more accustomed to thinking about it as an addiction, and they are simply more familiar with it (Stellin, 2018). In other words, for better or worse, "addict" may be more socially normative label and therefore relatively less stigmatizing in certain respects.

Of course, although on the surface it seems encouraging that PFL likely increased readers' perceptions of how competent people with OUD are, it should be noted that this is not necessarily a positive finding in all contexts. Increased perceptions of competence might lead 
non-users to think that people who are "opioid addicts" are in control of their situation therefore personally responsible for any disadvantages. This perception could lead to feelings of hostility and resentment. As research has shown, increased competence can be perceived as a threat (Boyer \& Parren, 2015). The experiment conducted asked participants to read articles about various topics and people. Results found that increased competence was driven by the perception of potential danger. Applying this information to this study, participants most likely perceived those discussed in the "opioid addicts" condition to be a possible threat. This could explain why competence was increased for "people who are opioid addicts" and not "people who have an opioid use disorder." When a group is perceived as dangerous, perceived competence can be increased because that group is thought to be a threat.

Previous studies have parceled substance use disorders and alcohol use disorders out to understanding stigmatizing effects (Corrigan, et al., 2009; Kulesza, Larimer, \& Rao, 2013; McLaughlin \& Long, 1996). This is interesting because the other questions did ask about opioid use disorder or addiction without mentioning alcohol. Based on former literature, it was expected that the interpersonal experience that would yield the highest significance would have asked about opioid use disorder or addiction solely. Because the question about interpersonal experience asked about alcohol use disorder as well, it is an interesting find.

Beyond the use of PFL, another aspect of the article that might have been more influential than the labels for OUD was the focus on a "treatment center." The experimental articles were about a community dispute, but the heart of the community dispute was about a facility where people with OUD could go to get better. No aspect in the article featured a debate about whether people with OUD would or could get better, or whether they were willing to recover. Arguably, the framing of the article could have implied to readers that OUD is treatable, 
it's just a matter of where. McGinty, et al. (2016) argued that much of the media coverage of the opioid epidemic frame the opioid epidemic as a criminal activity problem, rather than a treatable health condition. With the fabricated article in this study simply implying that those with opioid use disorder or who are addicted to opioids could get better, perceptions could be improved.

Previously, this study argued that people with a "disorder" would be perceived as more warm than people with "addictions," (therefore eliciting less contempt and greater pity) because they were more likely to be seen as less blameworthy (Yang, et al., 2017). The article's emphasis on treatment, however, might have made people with OUD seem equally less blameworthy—at least in the case of "addicts." Providing some support for this possibility, Schwartz, Myers, and Astrachan (1974) found that negative attitudes toward people with mental illness were decreased when discussion of rehabilitation was introduced. Using an experiment, the researchers found that when the term rehabilitation was used in narratives about people with mental illness, people's desire to social distance themselves from this group decreased. Similarly, Mauer (2017) has argued that the use of terms like "rehabilitation," "treatment," and "recovery" can make people think about how a person is taking responsibility for themselves, and lead to greater feelings of empathy. In this way, the topic of the article - a proposed treatment center - could have washed out any effects of the labels for OUD on people's perceptions. If this interpretation is correct, the results of this study should be taken with some caution. Increased willingness to engage in passive facilitation may not accompany any article about "people with addiction." This effect could simply be limited to "people with addiction" who are associated treatment to some extent.

Finally, another possibility is that news stories could help make people see others as individuals, rather than groups, just by virtue their focus on individuals. News stories typically 
rely on exemplars, or examples of the issues they cover (e.g., Zillmann, Gibson, Sundar, \& Perkins, 1996), and in doing so they highlight unique and individual circumstances that could make people focus more on individual characteristics, beyond group categories. The articles focus on a community wrestling with the issue of opioid use that featured the voices of individual community members, may have had something of a de-categorizing effect on how people think about those struggling with OUD. The possibility that news exemplars could have these positive effects is an area that deserves additional research.

Practically speaking, this study has a few implications for our understanding of how journalism might influence perceptions on the opioid crisis, and it paves the way for additional research in this area. This research did not set out to test the effects of PFL, but nonetheless, the findings suggest that news reports would be wise to use it. Although, based on the findings from this research, it seems advisable for journalists to use PFL when covering the opioid crisis, it is not well understood how common it is for reporters to use this language. In fact, given the farreaching effects of the opioid epidemic, it is surprising how little research there is on the media coverage of the crisis at all. To this authors knowledge, there are currently few published studies examining how person-first language is used to depict opioid users in the media at large, let alone any studies that examine the language that is used by the news media to describe people with OUD (McGinty, Stone, Kennedy-Hendricks, \& Barry, 2019). Although this study did not find that different labels for OUD in a news story had any unique effects on readers' stereotypes, emotions, and behavioral intentions, it is only a single study, of a single article, comparing only two labels. A more extensive research program is needed that is aimed at examining the broader context of how these labels and other language that this study did not examine (e.g., "opioid user, junkie, getting clean, or opioid abuser") are used by different media outlets, and collectively 
affect the public stigmatization of OUD. A good first step may be to first understand how journalists reporting on the crisis are already currently labeling OUD, and how commonly PFL is being used, using content analysis methods. Furthermore, although this study focused on labels used in a news article, it is important to acknowledge that these labels may play a key and potentially different role in non-media communication as well. Future research should examine the perceptual effects of different labels (and PFL) used to describe people with OUD in healthcare contexts as well as in everyday conversations between the public.

Although the labels in this study did not have the predicted effects on stereotypes, emotions, and discrimination, it is worth noting that many of the variable relationships that were uncovered in this research are consistent with predictions of the BIAS Map (Cuddy, et al., 2007). For example, as could be expected, warmth was negatively correlated with contempt and positively correlated with pity. Pity was also correlated with active facilitation as predicted (both the original measure of active facilitation and the applied measure created for this research). However, there were several deviations from the BIAS Map that should be noted. For one, contempt was unrelated to applied active harm. Respondents who felt more contemptuous towards people with OUD were no more or no less in favor of policies that would penalize them. Although not entirely consistent with the BIAS Map, this is somewhat encouraging. Despite feeling some disdain towards opioid users, these negative feelings were not associated with ill will.

Yet, surprisingly, although warmth was positively associated with applied active facilitation, it was also positively associated with active harm. Put differently, respondents who had stronger feelings of affinity for people with OUD also tended to express greater support for policies that could help and harm them. Before dissecting this seemingly perplexing finding at greater length, it is important to note that although the measures of applied active harm and active 
facilitation created for this research were positively correlated with Cuddy et al.'s (2007) original measures of active facilitation and active harm, they were not strongly correlated (applied active harm and original active harm were modestly correlated, $r=.11$, and applied active facilitation and original active facilitation were moderately correlated, $r=.26$ ). Thus, the applied measures created for this study are far from perfect behavioral proxies for active facilitation and active harm.

This suggests that respondents probably did not view policies such as increase incarceration time for people convicted of using drugs or decreased government programming to benefit drug users as purely punitive. Nor did they see efforts to build treatment centers or donate or allocate money to keep users sober to be purely helpful. With this in mind, it seems that one possible reason for the perplexing finding that warmth was correlated with applied active harm as well as facilitation is that respondents regarded penalization as a "tough love." Perhaps the more warmth participants felt towards individuals with OUD, the more they may have supported policies that the believed could ultimately help them, even if those policies were punishing in nature.

If this interpretation of this correlation is correct it is somewhat discouraging because it suggests that punitive policies against people with opioid use disorder are for their own good. Such beliefs may be at best misguided and at worst damaging because it adds to the shame the person struggling with addiction already feels (O’Connor, Berry, Inaba, Weiss, \& Morrison, 1994; Sack, 2014). Sack (2014) argued that the idea of tearing drug users down or imposing harsher punishments to fix the opioid use problem, actually skirts the issues at hand. The thought that "tough love" or using punitive measures to make people who use opioids aware of their problems causes more psychological damage, focusing on addiction being a choice, rather than an illness or disease (Sack, 2014). By engaging in punitive punishments as a way to deal with "misbehavior," 
non-opioid users and supporters of punitive measures, are not helping people who use opioids stop the use, rather creating opportunity for further stigmatization.

O'Connor, et al. (1994) and Zarkin, et al. (2012) stated that treatment is the most effective way to help opioid users understand their disorder and harsh punishments do not provide the rehabilitation users need, rather increase taxpayer money funneled into incarceration facilities for healthcare costs and incarceration costs. According to the National Association of Drug Court Professionals, drug courts divert opioid users from incarceration sentences, but also provide treatment options, assisting in the opioid users getting better for the time being as well as for the future (NADCP, 2019). "Pull yourself up by your bootstraps" is a colloquial phrase, often used that could do more damage than good. By enacting harsher punishments, thinking it is for the opioid users own good and will help them take control or "pull themselves up by their bootstraps" leads to further psychological damage and repeat drug use (NADCP, 2019; O'Connor, et al., 1994; Sack, 2014; Zarkin, et al., 2012). Sack (2014) argued that people who use opioids already feel shame and guilt for their actions, when harsher punishments are enacted or telling people who are addicted to opioids to just stop and correct the problem, feelings of guilt and shame are increased. These feelings are increased when the person who is addicted to opioids realizes they are unable to make this change themselves (e.g., "pull themselves up by their bootstraps") and require help from treatment facilities and trained healthcare staff. This is especially problematic because seeking help is not seen as a way to solve the problem by one's own volition and leads to increased chances of relapse and psychological damage (NADCP, 2019; Sack, 2014; Zarkin, et al., 2012).

Of course, an important caveat to all of this research is that the relationships uncovered here likely only apply for individuals without direct experience with opioid use disorder. People who reporting having had a substance use disorder were not included in the final sample, and 
people's personal experience with a substance use disorder (in the form of having a close personal connection with someone who has had a substance use disorder) was used as a statistical control in this study's analyses. But notably, this variable was related to key variables of interest. For instance, personal experience negatively predicted contempt towards people with OUD, suggesting that people who had loved ones affected by substance use disorders were able to see past the negative stereotypes associated with this group. This underscores the point that even if news articles are able to influence public perceptions of people with opioid use disorder, they are not as influential as people's personal experiences.

\section{Limitations and Future Research}

There are several limitations with the current study, as well as opportunities for additional research that should be noted. One limitation of this research is its reliance on a MTurk workers. Although MTurk provides a convenience sample that that is more representative of the general population than an arguably more typical samples of undergraduate students, it is not representative in many ways. For instance, a large proportion of the participants had some sort of higher education. According to the US Census Bureau (2017), one-third of the population had an Associate's degree or higher. In this study, over half of the sample had an Associate's or Bachelor's degree, with about $20 \%$ of participants having obtained a Master's degree or higher. These numbers are significantly higher than the population in the United States. It is typically thought that those with higher education training and degrees think more critically than those without (Schroeder, 2019). Education was controlled for in this study's analyses, but nonetheless, the way that participants in the current study responded to the stimuli articles cannot necessarily be generalized to the larger population. For this reason, research with a more representative sample would be advantageous. 
MTurk workers have also been criticized as being professional survey takers. Many MTurk workers take surveys are a significant source of income and so they spend a lot of time taking them (Hauser, et al., 2019). This is problematic because MTurk workers could be more accustomed to research methods (e.g., more aware of researcher hypotheses) and therefore more susceptible to a response bias in which they respond in ways that do not match their true beliefs.

Because this research employed an experimental design, with tightly controlled conditions where the only thing that differed between the experimental stimuli was the labels used, a strength of this research was its internal validity. Although there were not many differences between the "addict" and "disorder" condition, there can be a fairly high level of confidence that any differences that did emerge were due to the label used. Yet, in order to exercise this level of experimental control, this study did make a lot of compromises in terms of ecological validity. Ecological validity refers to how well the findings mimic behaviors in real life (Wilkes Musso, Barker, Gouvier, 2020). There are several reasons that the study might have seemed artificial to the participants. For one, the articles fabricated for this research were taken out of the context of a news website. They lacked many details that participants might be used to encountering, such as advertisements, social media links, links to the news organizations online homepage, and links to other stories. Participants were not given the freedom to interact with the article as they may be accustomed to when they read news online. Also, participants were not even given a choice about reading the article. The articles in this study may not be the type of thing they ordinarily would choose to read. Participants may read and respond to opioid-related news very differently in a more natural environment. Relatedly, the topic of the experimental articles was probably not very salient to participants. The article was set in a (fictious) community that was unfamiliar to participants. As such, participants were likely not very 
invested in the topic of a treatment center because they felt personally unaffected by it. The lack of personal involvement with the story may have adversely affected participants' attention to the experimental articles, and it may have led to participants underestimating their reaction to the articles in their survey responses. Future research could improve on these issues by studying people's impressions of real news on the opioid crisis that they have consumed as a part of their natural news diet.

To make sense of the findings in this research, a handful of speculations were offered about how characteristics related to the experimental news articles (besides the labels) could have influenced reader's perceptions. But these are, after all, just speculation at this point. All the suggested possibilities need to be formerly tested. For example, the results of this research suggest that PFL may have been responsible for the relatively positive effects of the "addict" label in this study. An experiment that manipulates the addition of PFL to descriptions of addicts could test this. Furthermore, such a study could shed light on some of the mechanisms for these effects. Variables such as empathy could mediate the effects of PFL on improved perceptions, but possibilities such as these stand to be explored further.

This research is also limited by its use of non-validated measures for the outcome variables of interest. Measures of applied active harm and applied active facilitation were created for this study in the interest of tapping into people's real-world behavioral intentions. However, because these scales are not validated there is no guarantee what they are true measures of active harm and active facilitation. In fact, as previously discussed, the correlations of these variables with other measures including those used by Cuddy et al. (2007) in the original tests of the BIAS Map, suggests that they are likely not the purest measures of active harm and active facilitation. 
Finally, although this study uncovered some interesting patterns in people's perceptions, it should be noted that most of the findings did not reach a threshold of traditional statistical significance. Thus, there is a greater probability that the relationships that were observed in this research were due to chance. For this reason, all the findings in this study should be discussed with some caution and skepticism.

\section{Conclusion}

The public stigmatization of people with OUD can have devastating effects on people who suffer from the disorder and their chances of recovery. Although some past research has suggested that the labels used to describe people with OUD can act as vehicles for this stigma, this research was unable to replicate these findings. This research does hint at the importance of using PFL in order to emphasize the humanity of people who have OUD. PFL, in conjunction with the label "addict" appears to have made them seem slightly more competent, and reduced feelings of contempt felt toward this group. The results of this research underscore the importance of journalists and perhaps the public in general, of adopting a person-first approach to OUD (and perhaps any "addiction"), to encourage people to consider people as individuals instead lumping them into a broad social category. 


\section{References}

American Psychological Association. (2020). Publication manual of the American Psychological Association ( $7^{\text {th }}$ ed.). Washington, DC: American Psychological Association.

Ashford, R. D., Brown, A. M., Ashford, A., \& Curtis, B. (2019). Recovery dialects: A pilot study of stigmatizing and nonstigmatizing label use by individuals in recovery from opioid use disorders. Experimental and Clinical Psychopharmacology, 1-6.

Ashford, R. D., Brown, A. M., \& Curtis, B. (2019). “Abusing addiction”: Our language still isn’t good enough. Alcoholism Treatment Quarterly, 37, 257-272.

Ashford, R. D., Curtis, B., \& Brown, A. M. (2018). Substance use, recovery, and linguistics: The impact of word choice on explicit and implicit bias. Drug \& Alcohol Dependence, 189, 131-138.

Becker, J. C., \& Asbrock, F. (2012). What triggers helping versus harming of ambivalent groups? Effects of the relative salience of warmth versus competence. Journal of Experimental Social Psychology, 48, 19-27.

Boyer, P., \& Parren, N. (2015). Threat-related information suggests competence: A possible factor in the spread of rumors. PLoS One, 10, e0128421

Bye, H. H., \& Herrebroden, H. (2018). Emotions as mediators of the stereotype - discrimination relationship: A BIAS map replication. Group Processes \& Intergroup Relations, 21, 1078-1091.

Center for Disease Control and Prevention. (2013). Prescription painkiller overdoses: A growing epidemic, especially among women. $C D C$. Retrieved from http://www.cdc.gov/vitalsigns/prescriptionpainkilleroverdoses/index.html 
Center for Disease Control and Prevention. (2016). Prescription opioid overdose data. CDC. Retrieved from http://www.cdc.gov/drugoverdose/data/overdose.html

Center for Substance Abuse Treatment. (2004, Apr 12). Substance use disorders: A guide to the use of language. CSAT. Retrieved from https://www.naabt.org/documents/Languageofaddictionmedicine.pdf

Chandler, J., \& Shapiro, D. (2016). Conducting clinical research using crowdsourced convenience samples. Annual Review of Clinical Psychology, 12, 53-81.

Chandler, J., Mueller, P., \& Paolacci, G. (2014). Nonnaiveté among Amazon Mechanical Turk worker: Consequences and solutions for behavioral researchers. Behavioral Research Methods, 46, 112-130.

Collier, R. (2012). Person-first language: Noble intent but to what effect? The Canadian Medical Association Journal, 184, 1977-1978.

Congress Public Law. (2010). $111^{\text {th }}$ congress public law. Retrieved from https://www.congress.gov/111/plaws/publ256/PLAW-111publ256.pdf.

Corrigan, P. W., Green, A., Lundin, R., Kubiak, M. A., \& Penn, D. L. (2001). Familiarity with and social distance from people who have serious mental illness. Psychiatric Services, $52,953-958$.

Corrigan, P. W., Kuwabara, S. A., \& O’Shaughnessy, J. (2009). The public stigma of mental illness and drug addiction: Findings from a stratified random sample. Journal of Social Work, 9, 139-147.

Corrigan, P. W., \& Watson, A. C. (2002). Understanding the impact of stigma on people with mental illness. World Psychiatry, 1, 16-20. 
Crandall, C.S. \& Reser, A.H. (2005). Attributions and anti-fat bias. In K.D. Brownell, R.M. Puhl, \& M.B. Schwartz (Eds.) Weight Bias: Nature, consequences and remedies (pp. 83-96). New York: Guilford.

Crocker, A. F., \& Smith, S. N. (2019). Person-first language: Are we practicing what we preach? Journal of Multidisciplinary Healthcare, 12, 125-129.

Cuddy, A. J. C., Fiske, S. T., \& Glick, P. (2007). The BIAS Map: Behaviors from intergroup affect and stereotypes. Journal of Personality and Social Psychology, 92, 631-648. doi:10.1037/0022-3514.92.4.631

Feldman, D. B., \& Crandall, C. S. (2007). Dimensions of mental illness stigma: What about mental illness causes social rejection. Journal of Social and Clinical Psychology, 26, 37154.

Fischer, A. H., \& Roseman, I. J. (2007). Beat them or ban them: The characteristics and social functions of anger and contempt. Journal of Personality and Social Psychology, 93, 103115.

Fiske, S. T. (1998). Stereotyping, prejudice, and discrimination. In D. T. Gilbert, S. T. Fiske, \& G. Lindzey (Eds.), Handbook of social psychology (4th ed., pp. 357-411). Boston, MA: McGraw-Hill.

Fiske, S. T. (2018). Stereotype content: Warmth and competence endure. Association for Psychological Science, 27, 67-73.

Fiske, S. T., Cuddy, A. J. C., Glick, P. S., \& Xu, J. (2002). A model of (often mixed) stereotype content: Competence and warmth respectively follow from perceived status and competition. Journal of Personality and Social Psychology, 82, 878-902. 
Forgas, J. P. (2011). She just doesn't look like a philosopher...? Affective influences on the halo effect in impression formation. European Journal of Social Psychology, 41, 812-817.

Foster, C. R. (2017, Jul 14). The stigma of addiction is more dangerous than drug overdoses. Huffington Post. Retrieved from https:/www.huffpost.com/entry/the-stigma-ofaddiction-is-more-dangerous-than-drug_b_5968ee14e4b06a2c8edb45fe?guccounter=1

Goffman, E. (1963). Stigma: Notes on the management of a spoiled identity. Englewood Cliffs, NJ: Prentice-Hall.

Gosling, S. D., \& Mason, W. (2015). Internet research in psychology. Annual Review of Psychology, 66, 877-902.

Government of Western Australia, Department of Health. (2009). Creating a mentally healthy community. Department of Health. Retrieved from http://www.health.wa.gov.au/docreg/Education/Population/Health_Problems/Mental_Illn ess/Mentalhealth_stigma_fact.pdf

Granello, D. H., \& Gibbs, T. A. (2016). The power of language and labels: "The mentally ill" versus “people with mental illnesses." Journal of Counseling and Development, 94, 3140.

Harvard Health Publishing. (2011). Mental illness and violence. Harvard Medical School. Retrieved from https://www.health.harvard.edu/newsletter_article/mental-illness-andviolence

Hauser, D. J., Paolacci, G., \& Chandler, J. (2019). Common concerns with MTurk as a participant pool: Evidence and solutions. In F. R. Kardes, P. M. Herr, \& N. Schwarz (Eds.). Handbook of research methods in consumer psychology. New York, NY: Routledge. 
Hayes, A. F. (2018). Introduction to mediation, moderation, and conditional process analysis: A regression-based approach ( $2^{\text {nd }}$ ed.). New York, NY: Guilford.

Jahnke, S., Imhoff, R., \& Hoyer, J. (2015). Stigmatization of people with pedophilia: Two comparative surveys. Archive of Sexual Behavior, 44, 21-34.

Jones, E., Farina, A., Hastorf, A. H., Markus, H., Miller, D. T., \& Scott, R. A. (1984). Social stigma: They psychology of marked relationships. New York, NY: Freeman.

Kelly, J. F. (2017). Does it really matter how we talk about addiction? Words can hurt when they reinforce misconceptions. Addiction \& Recovery, 101, 1.

Kelly, J. F., Dow, S. J., \& Westerhoff, C. (2010). Does our choice of substance related terms influence perceptions of treatment need? An empirical investigation with two commonly used terms. Journal of Drug Issues, 40, 805-818.

Kelly, J. F., \& Westerhoff, C. M. (2010). Does it matter how we refer to individuals with substance-related conditions? A randomized study of two commonly used terms. International Journal of Drug Policy, 21, 202-207.

Key, K. D., Ceremony, H. N., \& Vaughn, A. A. (2019). Testing two models of stigma for birth mothers of a child with fetal alcohol spectrum disorder. Stigma and Health, 4, 196-203.

Kushner, M. G., \& Sher, K. J. (1991). The relation of treatment fearfulness and psychological service utilization: An overview. Professional Psychology-Research and Practice, 22, 196-203.

Link, B. G. (1987). Understanding labeling effects in the area of mental disorders: An assessment of the effects of expectations of rejections. American Sociological Review, 52, 96-112. 
Link, B. G., Cullen, F. T., Struening, E. L., Shrout, P. E., \& Dohrenwent, B. P. (1989). A modified labeling theory approach to mental health disorders: An empirical assessment. American Sociological Review, 54, 400-423.

Link, B. G., \& Phelan, J. C. (1999). Labeling and stigma. In Aneshensel, C. S., Phelan, J. C. (eds.) Handbook of the Sociology of Mental Health, Handbooks of Sociology and Social Research. Boston, MA: Springer.

Link, B. G., \& Phelan, J. C. (2001). Conceptualizing stigma. Annual review of Sociology, 27, 363-385.

Lovett, M., Bajaba, S., Lovett, M., \& Simmering, M. J. (2018). Data quality from crowdsourced surveys: A mixed method inquiry into perceptions of Amazon's Mechanical Turk Masters. Applied Psychology, 67, 339-366.

Matthews, S., Dwyer, R., \& Snoek, A. (2017). Stigma and self-stigma in addiction. Journal of Bioethical Inquiry, 14, 275-286.

Maurer, D. D. (2017, Jan 9). How empathy and understanding are better responses to addiction than judgment and moralizing. Windward Way. Retrieved from https://windwardway.com/blog/empathy-understanding-better-responses-addictionjudgment-moralizing/

McDuffie, D. (2019). Using Amazon's Mechanical Turk: Benefits, drawbacks, and suggestions. Association for Psychological Science. Retrieved from https://www.psychologicalscience.org/observer/using-amazons-mechanical-turk-benefitsdrawbacks-and-suggestions

McGarty, C. (1999). Categorization in social psychology. Thousand Oaks, CA: Sage. 
McGinty, E. E., Kennedy-Hendrics, A., Baller, J., Niederdeppe, J., Gollust, S., \& Barry, C. L. (2016). Criminal activity or treatable health condition? News media framing of opioid analgesic abuse in the United States, 1998-2012. Psychiatric Services, 67, 405-411.

McGinty, E. E., Stone, E. M., Kennedy-Hendricks, A., \& Barry, C. L. (2019). Stigmatizing language in news media coverage of the opioid epidemic: Implications for public health. Preventative Medicine, 124, 110-114.

Murphy, K. R., Jako, R. A., \& Anhalt, R. L. (1993). Nature and consequences of halo error: A critical analysis. Journal of Applied Psychology, 78, 218-225.

Mushtaq, S., Mendes, V., Nikolaou, V., \& Luty, J. (2015). Analysis of the possible components of stigmatised attitudes towards depression and heroin dependence. Journal of Substance Use, 20, 399-406.

National Association of Drug Court Professionals. (2019). Drug courts are criminal justice reform. $N A D C P$. Retrieved from https://www.nadcp.org/wpcontent/uploads/2020/03/Drug-Court-Fact-Sheet-2020.pdf

National Center on Birth Defects and Developmental Disabilities. (2017). Communicating with and about people with disabilities. $N C B D D D$. Retrieved from https://web.archive.org/web/20171213144444/https://www.cdc.gov/ncbddd/disabilityand health/pdf/disabilityposter_photos.pdf

National Center on Disability and Journalism. (2016, Jan 7). Journalists should learn to carefully traverse a variety of disability terminology. $N C D J$. Retrieved from https://ncdj.org/2016/01/journalists-should-learn-to-carefully-traverse-a-variety-ofdisability-terminology/ 
Nieweglowski, K., Corrigan, P. W., Tyas, T., Tooley, A., Dubke, R., Lara, J., Washington, L., Sayer, J., \& Sheehan, L. (2017). Exploring the public stigma of opioid use disorder through community-based participatory research. Addiction Research and Theory, 26, 323-329.

Nieweglowski, K., Dubke, R., Mulfinger, N., Sheehan, \& Corrigan, P. W. (2019). Understanding the factor structure of the public stigma and opioid use disorder. Addiction Research and Theory, 27, 156-161.

Oakes, P. (2003). The root of all evil in intergroup relations? Unearthing the categorization process. In R. Brown \& S. Gaertner (Eds.), Blackwell handbook of social psychology: Intergroup processes (pp. 3-21). Malden, MA: Blackwell.

O’Connor, L. E., Berry, J. W., Inaba, D., Weiss, J., \& Morrison, A. (1994). Shame, guilt, and depression in men and women in recovery from addiction. Journal of Substance Abuse Treatment, 11, 503-510.

Ortmann, A., \& Hertwig R. (2002). The costs of deception: Evidence from psychology. Experimental Economica, 5, 111-131.

Pescosolido, B. A., Monahan, J., Link, B. G., Stueve, A., \& Kikuzawa, S. (1999). The public's view of the competence, dangerousness, and need for legal coercion of persons with mental health problems. American journal of public health, 89, 1339-1345.

Ross, J., Irani, L., Silberman, M., Six, Zaldivar, A., \& Tomlinson, B. (2010). Who are the crowdworkers?: Shifting demographics in Amazon Mechanical Turk. CHI Extended Abstracts, 2863-2872.

Russell, A. M. T., \& Fiske, S. T. (2008). It's all relative: Competition and status driver interpersonal perception. European Journal of Social Psychology, 38, 1193-1201. 
Sack, D. (2014, Oct 13) 5 ways we punish addicts - And why we should stop. Psychology Today. Retrieved from https://www.psychologytoday.com/us/blog/where-science-meetsthe-steps/201410/5-ways-we-punish-addicts-and-why-we-should-stop

Sadler, M. S., Kaye, K. E., \& Vaughn, A. A. (2015). Competence and warmth stereotypes prompt mental illness stigma through emotions. Journal of Applied Social Psychology, $45,602-612$.

Scheff, T. J. (1966). Being mentally ill: A sociological theory. New York, NY: Routledge.

Scheff, T. J. (1984). Being mentally ill: A sociological theory (3 ${ }^{\text {rd }}$ ed.). New York, NY: Routledge.

Schroeder, R. (2019, Jul 10). What matters more: Skills or degrees. Inside Higher Ed. Retrieved from https://www.insidehighered.com/digital-learning/blogs/online-trending-now/whatmatters-more-skills-or-degrees

Schwartz, C. C., Myers, J. K., \& Astrachan, B. M. (1974). Psychiatric labeling and the rehabilitation of the mental patient: Implications of research findings for mental health policy. Archives of General Psychiatry, 31, 329-334.

Stellin, S. (2018). Using language around addiction that doesn't shame or stigmatize. Neiman Reports, 40.

Sundar, S. S. (1999). Exploring receivers' criteria for perception of print and online news. Journalism \& Mass Communication Quarterly, 76, 373-386.

Tajfel, H. (1978). Differentiation between social groups: Studies in the social psychology of intergroup relations. London: Academic Press. 
Tajfel, H., \& Turner, J. C. (1986). The social identity theory of intergroup behavior. In S. Worchel, \& W. G. Austin (Eds.), Psychology of intergroup relations (pp. 7-24). Chicago, IL: Nelson-Hall.

Tempalski, B., Friedman, R., Keem, M., Cooper, H., \& Friedman, S. R. (2007). NIMBY localism and national inequitable exclusion alliances: The case of syringe exchange programs in the United States. Geoforum, 38, 1250-1263.

U.S. Census Bureau. (2017, Mar 30). Highest educational levels reached by adults in the U.S. since 1940. United States Census Bureau. Retrieved from https://www.census.gov/newsroom/press-releases/2017/cb17-51.html

Vaughn, A. A., Teeters, S. A., Sadler, M. S., \& Cronan, S. B. (2017). Stereotypes, emotions, and behaviors toward lesbians, gay men, bisexual women, and bisexual men. Journal of Homosexuality, 64, 1890-1911.

Volavka, J. (2013). Violence in schizophrenia and bipolar disorder. Psychiatria Danubina, 25, 24-33.

Wehmeyer, M., Bersani, H. J., \& Gagne, R. (2000). Riding the third wave: Self-discrimination and self-advocacy in the $21^{\text {st }}$ century. Focus on Autism and Other Developmental Disabilities, 15, 106-115.

Wilkes Musso, M., Barker, A. A., \& Gouvier, W. D. (2020). Ecological validity: Psychology. Britannica. Retrieved from https:/www.britannica.com/science/ecological-validity

Wright, E. R., Gronfein, W. P., \& Owens, T. J. (2000). Deinstituionalization, social rejection, and the self-esteem of former mental patients. Journal of Health and Social Behavior, 41, $68-90$. 
Yang, L., Wong, L. Y., Grivel, M. M. Hasin, D. S. (2017). Stigma and opioid use disorders: An international phenomenon. Current Opinion in Psychiatry, 30, 378-388.

Zamarro, G. (2018, May). When survey respondents don't pay attention. The Evidence Base. Retrieved from https://healthpolicy.usc.edu/evidence-base/when-survey-respondentsdont-pay-attention/

Zarkin, G. A., Cowell, A. J., Hicks, K. A., Mills, M. J., Belenko, S., Dunlap, L. J., \& Keyes, V. (2012). Lifetime benefits and costs of diverting substance-abusing offenders from state prison. Crime and Delinquency, 61, 829-850.

Zillmann, D., Gibson, R., Sundar, S.S., \& Perkins, J.W. (1996). Effects of exemplification in news reports on the perception of social issues. Journalism and Mass Communication Quarterly, 73, 427. 


\section{Appendix A \\ Amazon Mechanical Turk Survey Advertisement \\ Opinions About a Local Social Issue}

Researchers at West Virginia University are conducting a research study about a social issue affecting a local community. If you would like to participate, you will be asked to:

- Read a short online news article

- Tell us your opinion about the article and the social issue by answering survey questions.

You must be at least 18 years old to complete this study.

The study takes about 15 minutes to complete.

The survey is available online.

There are no known benefits of participating in this research.

IRB acknowledgement is on file for this study (protocol \#2001854620).

Select the link below to complete the survey. When you have finished the survey, please enter the code provided at the end of the survey in the box below to receive $\$ 1.43$ payment. After it's confirmed that you completed at least $90 \%$ of the survey, your payment will be transferred to your MTurk account within 3 days.

Thank you for your help!

Kylie J. Wilson (doctoral candidate)

(kw0059@mix.wvu.edu)

Elizabeth Cohen, $\mathrm{PhD}$

(elizabeth.cohen@mail.wvu.edu)

West Virginia University

Department of Communication Studies

PO BOX 6293

Morgantown, WV 26505-6293

elizabeth.cohen@mail.wvu.edu

Survey link:

https://wvu.qualtrics.com/jfe/form/SV_1BUBvWRehD00CVv 
Appendix B

Consent Information Form

$\begin{array}{ll}\text { Principal Investigator (PI) } \mid & \text { Elizabeth L. Cohen } \\ \text { Department } \mid & \text { Communication Studies } \\ \text { WVU IRB Protocol \# } \mid & \text { 2001854620 } \\ \text { Study Title } \mid & \text { Opinions about a Local Social Issue }\end{array}$

Why is this research being done and what is involved?

The purpose of this study is to better understand how people form impressions of social issues and the people associated with those issues. If you decide to participate, you will first be asked to read an online article about a social issue affecting a local community. Next you will be asked to complete an online survey about your opinions about the issue the articles described plus some other local community issues. From start to finish the online study should take you approximately 15 minutes to complete.

Do I have to participate and what are the risks?

Risks from participation in this study include discomfort from some questions in the survey asking about personal experience with substance use disorder. Should you become uncomfortable or upset at any time, or if you simply no longer wish to continue your participation after you start for any reason, you may skip the questions or stop participating. Your participation in this research study is completely voluntary and you are free to withdraw from the research at any time.

There are no known benefits of this research.

Will I be compensated for my participation?

You will be paid $\$ 1.43$ in your Mechanical Turk account for completing at least $90 \%$ of the survey. The funds will be deposited within 3 days of completion. If you withdraw before completing $90 \%$ of the survey you will not be compensated.

\section{What will happen to my research information and data?}

Any information about you that is obtained as a result of your participation in this research will be kept as confidential as legally possible. Your research records, just like hospital records, may be subpoenaed by court order or may be inspected by the study sponsor or federal regulatory authorities, including the Food and Drug Administration (FDA), without your additional consent. In addition, there are certain instances where the researcher is legally required to give information to the appropriate authorities. These would include mandatory reporting of infectious diseases, mandatory reporting of information about behavior that is imminently dangerous to you or to others, such as suicide, child abuse, etc. 
Your participation in this research is anonymous. The researchers will have no way to link your responses to your identity. In any publications that result from this research, neither your name nor any information from which you might be identified will be published.

\section{Who can I talk to if I have questions or concerns?}

If you have any questions or concerns about this research, you can contact Dr. Elizabeth L. Cohen, PhD at Elizabeth.Cohen@mail.wvu.edu or Kylie J. Wilson at kw0059@mix.wvu.edu from the Department of Communication Studies at West Virginia University.

For information regarding your rights as a participant in research or to talk about the research, contact the WVU Office of Human Research Protection (OHRP) at (304) 293-7073 or by email at IRB@mail.wvu.edu.

I willingly agree to be in the study.

○ Yes

○ No 
Appendix C

Stimulus Materials

I. Addiction Label Condition (label manipulations are indicated with boldface)

Smithville Residents Pack Hearing over Controversial Proposal to Open Opioid Addiction Treatment Center

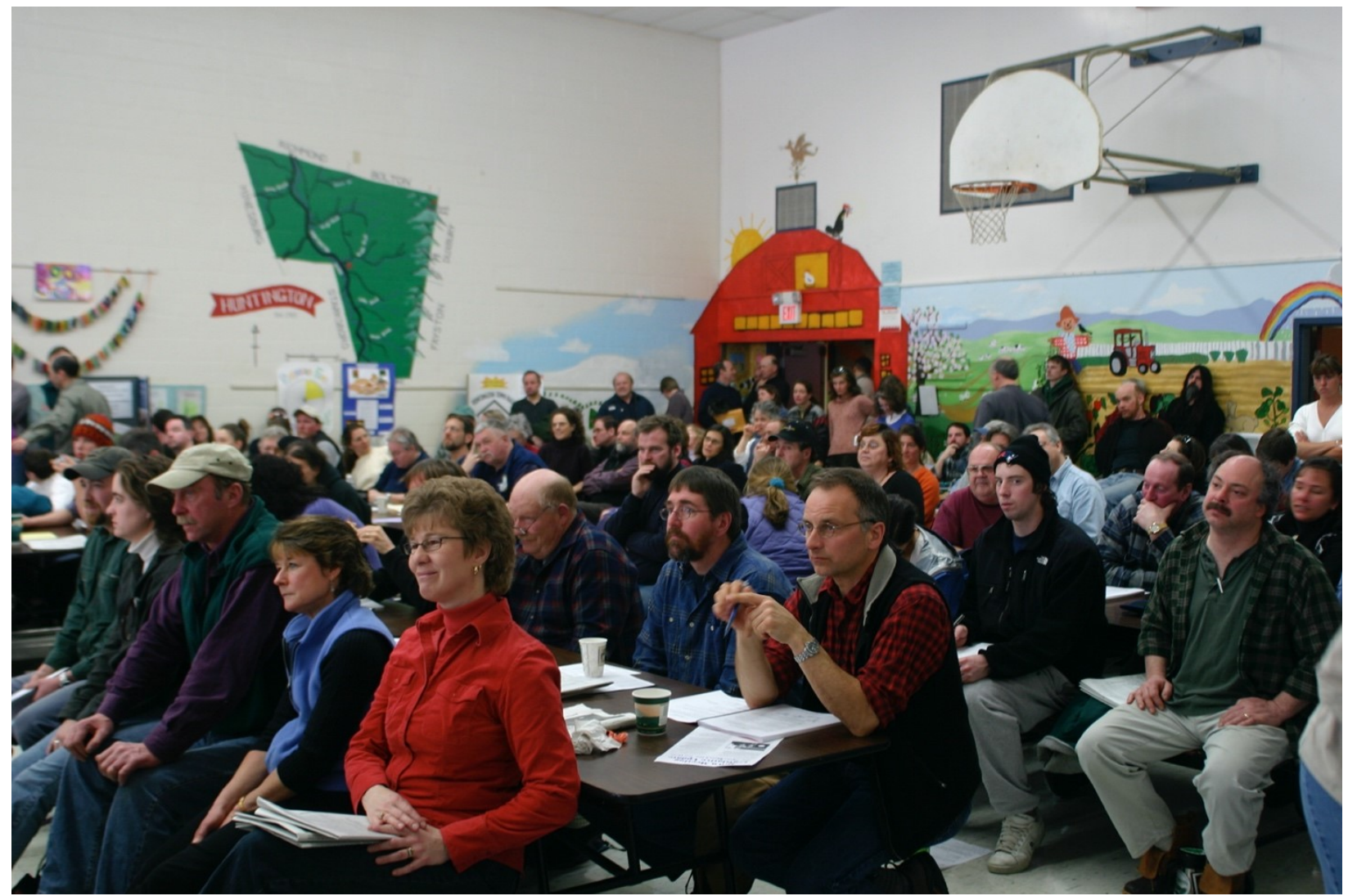

Residents pack the gymnasium for hearing over proposed opioid addiction treatment center before the final vote from the board.

Smithville. - Controversy over a proposed opioid addiction treatment center continued in the northwest suburbs Wednesday. 
Concerned residents packed the Smithville High School gymnasium for the first of several public hearings on a proposal to bring an opioid addiction treatment center to the town.

The opioid crisis began in the late 1990s when the medical community was not informed that patients could become addicted to pain relievers and healthcare providers began prescribing them at greater rates. Increased prescription of opioid medications led to widespread use of both prescription and non-prescription opioids before it became clear that these medications could indeed lead to addiction.

According to the U.S. Department of Health and Human Services, more than 130 people die every day from opioid addiction, resulting in more than 47,000 deaths a year.

Many communities like Smithville are feeling the negative effects of the opioid epidemic intensely. The northwest suburb has seen a two-fold increase in opioid addiction rates in the past year.

"I've had encounters with a lot more people who are struggling with opioid addiction in the last few months. Seems like they're everywhere. And it happened so fast," said Emily Miller, longtime Smithville resident and owner of a neighborhood convenience store. "It seems like they all got addicted overnight."

The Haymarket Center, an addiction treatment organization, stated that addicts in Smithville could benefit from treatment centers, clean needle exchange programs, or supervised injection sites. That is why the Haymarket Center is planning to build a facility in Smithville. The organization plans to turn a building that was formerly a Holiday Inn into an opioid addiction treatment center with more than 200 beds.

Proponents of the plan see the facility as a good first step to helping people who are opioid addicts and lessening the town's burden. "Maybe we wouldn't feel so overwhelmed by the opioid crisis if we had some more help. They need a place to go. They need help. Giving them better access to opioid addiction treatment will improve everybody's quality of life in town," said Christopher Jones, a retired high school principle in attendance.

However, opponents of the plan argue that locating an opioid addiction treatment Smithville will create more problems for the town. Speaking at the forum, Susan Nichols of East Smithville said that while she is "not insensitive to the need for opioid addiction treatment," she doesn't want Smithville to be the place people with addiction go to get it. "Opening doors to this facility will be like rolling out the welcome wagon for people with opioid addiction. It will encourage them to come to our town-- 
a very residential community. And ultimately we will have to pay the price for their addiction."

Officials representing The Haymarket Center gave a presentation to demonstrate how similar opioid addiction treatment programs have been implemented in neighboring towns. By the end of the meeting, residents seemed evenly split on whether or not they would welcome the proposed facility.

The city council will have the final say if an opioid addiction treatment center will come to town. A vote is scheduled for their monthly meeting on the first Tuesday of March. 
II. Opioid Use Disorder Condition (label manipulations indicated with boldface)

\section{Smithville Residents Pack Hearing over Controversial Proposal to Open Opioid Use Disorder Treatment Center}

POSTED 10:32 PM, FEB 2020, BY STAFF

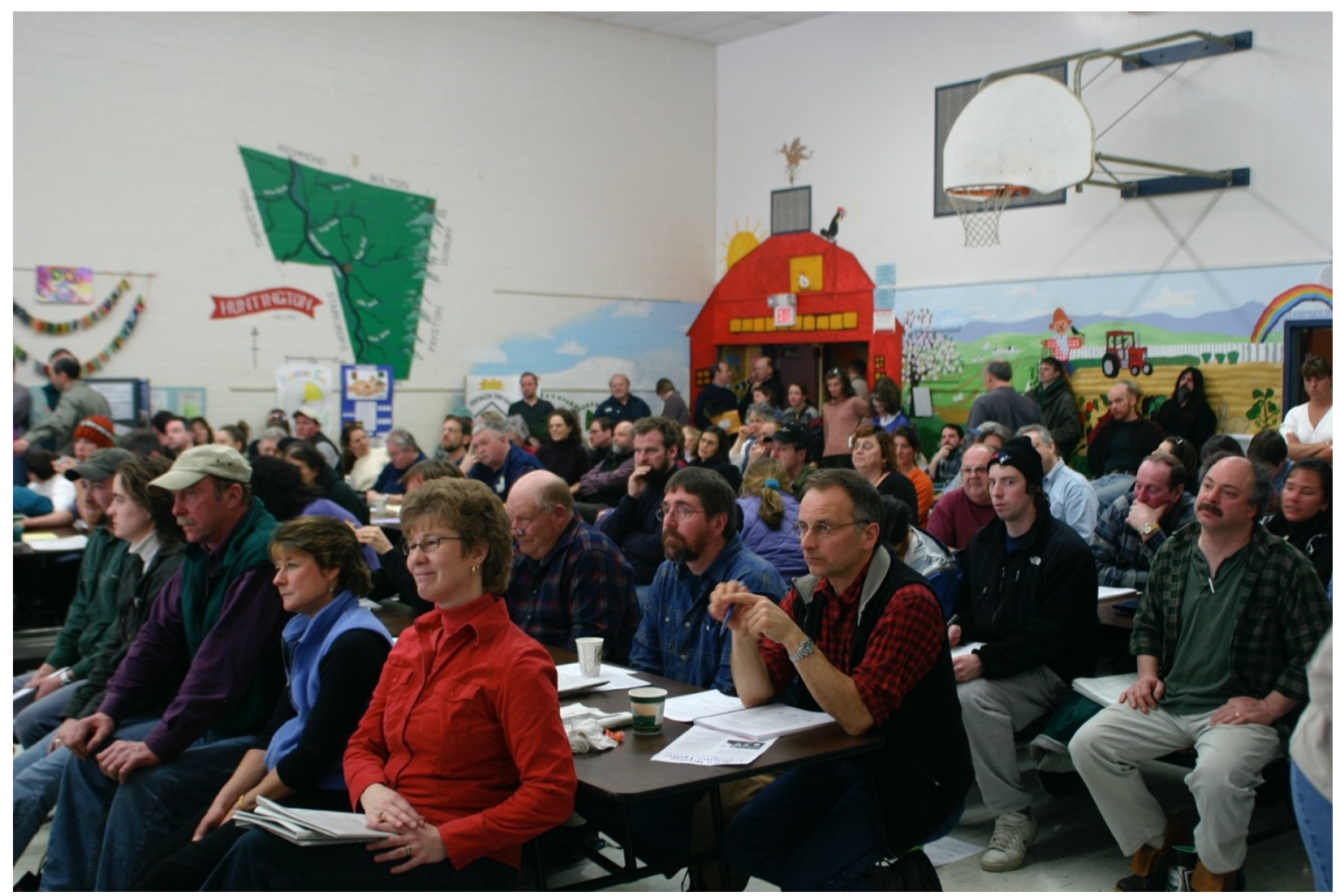

Residents pack the gymnasium for hearing over proposed opioid use disorder treatment center before the final vote from the board.

Smithville. - Controversy over a proposed opioid use disorder treatment center continued in the northwest suburbs Wednesday. 
Concerned residents packed the Smithville High School gymnasium for the first of several public hearings on a proposal to bring an opioid use disorder treatment center to the town.

The opioid crisis began in the late 1990s when the medical community was not informed that patients could develop a disorder to pain relievers and healthcare providers began prescribing them at greater rates. Increased prescription of opioid medications led to widespread use of both prescription and non-prescription opioids before it became clear that these medications could indeed lead to opioid use disorder.

According to the U.S. Department of Health and Human Services, more than 130 people die every day from opioid use disorder, resulting in more than 47,000 deaths a year.

Many communities like Smithville are feeling the negative effects of the opioid epidemic intensely. The northwest suburb has seen a two-fold increase in opioid use disorder rates in the past year.

"I've had encounters with a lot more people who are struggling with opioid use disorder in the last few months. Seems they're everywhere. And it happened so fast," said Emily Miller, longtime Smithville resident and owner of a neighborhood convenience store. "It seems like they all got the disorder overnight."

The Haymarket Center, an opioid use disorder treatment organization stated that addicts in Smithville could benefit from treatment centers, clean needle exchange programs, or supervised injection sites. That is why the Haymarket Center is planning to build a facility in Smithville. The organization plans to turn a building that was formerly a Holiday Inn into an opioid use disorder treatment center with more than 200 beds.

Proponents of the plan see the facility as a good first step to helping people with use disorder and lessening the town's burden. "Maybe we wouldn't feel so overwhelmed by the opioid crisis if we had some more help. They need a place to go. They need help. Giving them better access to opioid use disorder treatments will improve everybody's quality of life in town," said Christopher Jones, a retired high school principle in attendance.

However, opponents of the plan argue that locating an opioid use disorder treatment Smithville will create more problems for the town. Speaking at the forum, Susan Nichols of East Smithville said that while she is "not insensitive to the need for opioid use disorder treatment," she does want Smithville to be the place people with the disorder go to get it. "Opening doors to this facility will be like rolling out the welcome wagon for people with opioid use disorder. It will encourage them to come to our 
town--a very residential community. And ultimately we will have to pay the price for their disorder."

Officials representing The Haymarket Center gave a presentation to demonstrate how similar opioid use disorder treatment programs have been implemented in neighboring towns. By the end of the meeting, residents seemed evenly split on whether or not they would welcome the proposed facility.

The city council will have the final say if an opioid use disorder treatment center will come to town. A vote is scheduled for their monthly meeting on the first Tuesday of March. 
III. Control Condition

\section{Smithville Residents Pack Hearing over Controversial Proposal to Ban Ownership of Certain Dog Breeds}

POSTED 10:32 PM, FEB 2020, BY STAFF

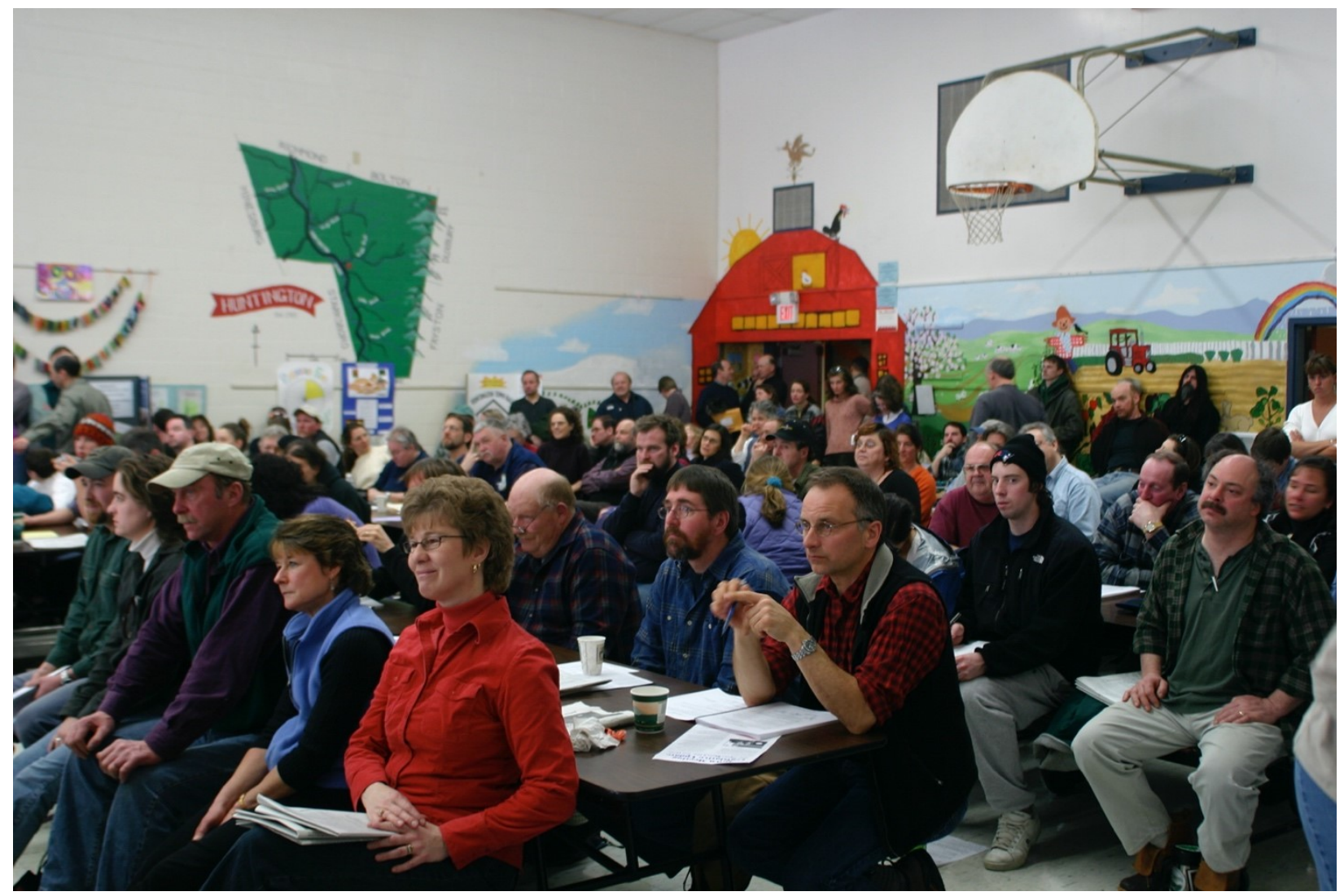

Residents pack the gymnasium for hearing over proposed bill to ban pit bulls from the city limits of Smithville.

Smithville. - Controversy over a proposed ban on the possession of certain breeds of dogs continued in the northwest suburbs Wednesday.

Concerned residents packed the Smithville High School gymnasium for the first of several public hearings on a proposal to pass legislation that would make it illegal to own certain types of dogs such as pit bulls if living within the city limits. 
An analysis by the research organization, STATISTA, shows that the Pit Bull is responsible for the most fatal attacks in the U.S. compared to other breeds, killing 284 people (66 percent of total fatalities) over a 13-year period.

Breed-specific legislation began popping up in towns in the early 1980 s following several fatalities and serious injuries that were linked to certain breeds of dogs such as pit bulls. These high-profile cases increased the perceived need for laws governing dog ownership.

Here in Smithville, the northwest suburb has seen a two-fold increase in reports of dog attacks in the past year.

"We've seen a lot more patients presenting with dog-related injuries in the few months. Seems there's at least one a week now," said Emily Miller, longtime Smithville resident and a medical technician at the town's urgent care clinic. "It's starting to feel a little more like an epidemic."

United Neighbors, a community safety advocacy group stated that Smithville could reduce the number of dog attacks by targeting dog breeds with a reputation for violence. The organization has lobbied for this legislation that would allow residents to keep pit bulls that they already own if they obtain a permit. New pit bulls would not be allowed at all.

Proponents of the plan see it as a necessary step to make the community safer. "There are places I feel uncomfortable walking in my own neighborhood because of some of how the dogs lunge at me form behind the fences. A pit bull ban would go a long way to making Smithville feel safe and welcoming again. I think I have a right to feel safe in my neighborhood," said Christopher Jones, a retired high school principle in attendance.

However, opponents of the ban argue that there is no evidence that breed-specific legislation is effective, and that these laws would be costly, and difficult to enforce. They might also not be addressing the real problem. Speaking at the forum, Susan Nichols of East Smithville said that while she is "not insensitive to residents' concerns about safety," she does not think a pit pull ban is the answer. "Data that claims to identify breeds that bite is notoriously inaccurate. But what the research does show is that dogs that bite are likely to have owners with violent criminal convictions. This is a people problem, not a dog problem. You can't solve a people problem with a ban on dogs.

Officials representing United Neighbors gave a presentation to demonstrate how similar legislation has been implemented in neighboring towns. By the end of the meeting, residents seemed evenly split on whether or not they would welcome the ban. 
The city council will have the final say if the breed-specific legislation will go into effect. A vote is scheduled for their monthly meeting on the first Tuesday of March. 
Appendix D

Survey Instrumentation

Thank you for agreeing to participate in this research study.

The first thing we would like you to do is spend some time reading a news article about an issue affecting a local community. Please read the article posted below carefully. You will be asked questions about it later.

After 45 seconds, if you have finished reading the article, you can then proceed to complete the survey.

[Participants randomly assigned to read one of three articles]

Thank you for reading the news article. Now we would like to ask you some questions about the article you just read.

I. Attention \& Manipulation Checks

First, in your own words, please tell us what the article you just read was about.

Considering the options below, which issue best describes what the article you read was about:

Public Transportation

A Proposed Treatment Center

Electing a New Mayor

Banning Pit Bulls

None of the Above

What group of people was the proposed treatment center supposed to help?

II. Article Impressions (Sundar, 1999)

Now, we are interested in knowing more your perceptions of the article. Please read the list of descriptions below and indicate how well you think they describe the article you just read on a scale of 1 (Not at All Descriptive) to 7 (Extremely Descriptive).

Credibility

Biased

Fair

Objective 
Liking
Boring
Enjoyable
Interesting
Lively
Pleasing
Quality
Accurate
Believable
Clear
Coherent
Comprehensive
Concise
Well-Written
Representativeness
Disturbing
Important
Relevant
Timely

III. Behavior (item order will be randomized)

For this next section, please think about your own community.

As a community member, please consider the policies or proposed solutions to different social issues mentioned below. How supportive do you think you would be of implementing the following ideas on a scale of 1 (Not Supportive At All) to 7 (Extremely Supportive).

How likely would you be to...

... support a proposition to build a treatment facility for people who use drugs in your community (AF)

... support a proposition to allocate tax dollars to support treatment programs for drug users in your community (AF)

... support a proposition creation of a needle exchange program to improve the health of drug users in your community (AF)

... donate money to support treatment programs for drug users in your community (AF)

... donate money to drug users trying to stay sober (AF)

... volunteer time at a treatment program for drug users in your community (AF)

... help people who use drugs in your community (AF)

... protect people who use drugs in your community (AF)

... support legislation that makes it harder for drug users to get jobs (AH)

... support legislation that makes it harder for drug users to benefit from government programs (AH) 
... support legislation for increased incarceration time for crimes committed by drug users (AH)

... support legislation for increased incarceration time for people convicted for using drugs (AH)

... support a proposition to relocate drug users in your community to another community (AH)

... fight people who use drugs in your community $(\mathrm{AH})$

... attack people who use drugs in your community (AH)

... support legislation to ban ownership of certain breeds of dogs such as pit bulls

... support legislation requiring people to obtain permits in order to own breeds of dogs like pit bulls in your community

... volunteer time at an animal shelter in your community

... donate money to support an animal shelter in your community

... put speed bumps in your neighborhood

$\ldots$ increase the speed limit in your neighborhood

... increase incarceration time for animal abuse

... relocate homeless people to another community

... build a homeless shelter in your community

IV. Stereotype Content Model and BIAS Map Emotions (Cuddy et al. 2007)

Thank you for answering those questions. Now we are going to switch gears!

For these next questions, we would like you to think about [PEOPLE WHO ARE OPIOID ADDICTS/PEOPLE WHO HAVE OPIOID USE DISORDER], as a group.

Please think about other people's perceptions of this group. Using the scale below, please indicate the extent that you are with the statements about how people in society view people who [are opioid addicts/have opioid use disorder] using the accompanying scale ( 1 = "Disagree Strongly" to 7 = "Agree Strongly").

People believe that...

... this group is competent.

... this group is confident.

... this group is independent.

... this group is competitive.

$\ldots$ this group is intelligent.

... this group is warm.

... this group is tolerant.

... this group is good natured.

$\ldots$ this group is sincere.

Now please think about people's emotions toward people who [are addicted to opioids/have opioid use disorder] and indicate the extent that you agree with the statements below.

People in society feel... 
... contempt towards this group.

... disgust towards this group.

... anger towards this group.

... this group has inferior morals.

... admiration towards this group.

... pride towards this group.

... pity towards this group.

... sympathy towards this group.

... sorry for this group.

... concerned for this group.

... envy towards this group.

... jealousy towards this group.

And for the final part of this section, please indicate about how other people want to behave towards or treat people [who are addicted to opioids/with opioid use disorder] and indicate how much you agree with the following statements.

People in society want to...

... help this group.

... protect this group.

... fight this group.

... attack this group.

... cooperate with this group.

... associate with this group.

... exclude this group.

... demean this group.

... sorry for this group.

... concern for this group.

... envy towards this group.

... jealousy towards this group.

V. Perceptions of Impact

For this next section, we are interests in knowing more about your personal perceptions of the opioid crisis and its impact.

Please use the slider below to indicate, in your best estimate, what perception of people who have an opioid use disorder or opioid addiction in different areas [0-100\%]

What percentage of people in YOUR COMMUNITY have an opioid use disorder? 
What percentage of people in THE UNITED STATES have an opioid use disorder?

What percentage of people IN YOUR STATE have an opioid use disorder?

For these next few items, please indicate how much you agree that you and different groups have been negatively affected by the opioid crisis. If you do not think there has been any effect, please mark 1. If you think there has been an extremely negative effect, please mark 7 using the scale of 1 "Strongly Disagree" to 7 "Strongly Agree."

YOU personally have been negative affected by the opioid crisis.

YOUR FRIENDS AND ACQUAINTANCES have been negatively affected by the opioid crisis. PEOPLE IN YOUR COMMUNITY in general have been negatively affected by the opioid crisis.

PEOPLE IN YOUR STATE have been negative affected by the opioid crisis. PEOPLE IN YOUR COUNTRY have been negatively affected by the opioid crisis.

And now, using the same scale but thinking of your own community, please indicate how much you agree with the following statements about how the opioid crisis may have negatively affected different aspects of your community.

The opioid crisis has had a negative impact on your community's economy.

The opioid crisis has had a negative impact on the physical health of the people in your community.

The opioid crisis has had a negative impact on the mental health of people in your community. The opioid crisis has had a negative impact on the safety of your community.

The opioid crisis has had a negative impact on the wellbeing of children and families in your community.

\section{Personal Experience with Substance Use}

Now we have some questions about your personal experience with drugs and alcohol use. Please remember that if you feel uncomfortable answering any of these questions you are free to skip them. Also, keep in mind that anything that you do report is completely anonymous - we will not be able to connect your identity to your answers.

Has anyone close to you had an opioid addiction or opioid use disorder?

Yes

No

Have you personally had an opioid use disorder or an opioid addiction?

Yes

No

Has anyone close to you had a use disorder or addiction to substances besides opioids?

Yes

No 
Have you personally had a use disorder or addiction to substances besides opioids?

$$
\begin{aligned}
& \text { Yes } \\
& \text { No }
\end{aligned}
$$

Has anyone close to you received professional treatment for drug or alcohol use disorder or addiction?

$$
\begin{aligned}
& \text { Yes } \\
& \text { No }
\end{aligned}
$$

Have you personally ever received professional treatment for a drug or alcohol use disorder or addiction?

$$
\begin{aligned}
& \text { Yes } \\
& \text { No }
\end{aligned}
$$

VII. Demographics

In this section, we'd like to ask a few more questions about yourself.

What is your current age (in years)?

With which gender do you most closely identify?

Male

Female

Transgender Male/Trans Man/Female-to-Male (FTM)

Transgender Female/Trans Woman/Male-to-Female (MTF)

Gender Variant/Non-conforming

Not Listed:

Prefer not to answer

With which race/ethnicity do you most closely identify?

White/Caucasian

Hispanic/Latino(a)

Black/African American

Native American/American Indian

East Asian/Pacific Islander

Middle Eastern/West Asian

Central Asian (e.g., Indian, Pakistani, Nepalese)

Other

Prefer not to answer

What is your highest level of education achieved?

Some High School

High School Diploma/GED

Some College

Associate's Degree 
Bachelor's Degree

Master's Degree

Doctoral Degree

Professional Degree

Other

In what U.S. State do you currently reside? (drop down options)

Do you live in the Appalachian Region?

Yes

No

What is your yearly household income?

$0-30,000$

$30,001-60,000$

$60,001-90,000$

$90,001-120,000$

$120,001-150,000$

$150,001+$

\section{Efforts}

Finally, we know that you are completing a lot of tasks and it's not always possible to pay close attention to surveys like these.

Your answer to this question will NOT affect any compensation or benefits that you were entitled to. Please answer based on the scale $0=$ No Effort At All, $4=$ A Great Deal of Effort.

In your honest opinion, how much effort did you put into paying attention to this study?

Thank you so much for your time! Your participation on this survey is invaluable and we are grateful for your contribution!

Please input your Mechanical Turk User ID into MTurk and the box below. It is a long string of letters and numbers that MTurk associates with your account. You can find it in the top right of your Mechanical Turk dashboard.

As soon as your survey has been checked for completeness, your account will be credited with \$1.43.

Enter your MTurk User ID here (also put your ID in the MTurk box for this survey):

If you or someone you know is struggling with a substance use disorder and would like more information, please use the link HERE for access to contact information and resources. 